\title{
Factors associated with early outcomes following standardised therapy in children with ulcerative colitis (PROTECT): a multicentre inception cohort study
}

\author{
JeffreyS Hyams, Sonia Davis, David R Mack, Brendan Boyle, Anne M Griffiths, Neal S LeLeiko, Cary G Saver, DavidJ Keljo, James Markowitz, \\ Susan S Baker, Joel Rosh, Robert N Baldassano, Ashish Patel, Marian Pfefferkorn, Anthony Otley, Melvin Heyman, Joshua Noe, Maria Oliva-Hemker, \\ Paul Rufo, Jennifer Strople, David Ziring, Stephen L Guthery, Boris Sudel, Keith Benkov, Prateek Wali, Dedrick Moulton, Jonathan Evans, \\ Michael D Kappelman, Alison Marquis, Francisco A Sylvester, Margaret H Collins, Suresh Venkateswaran, Marla Dubinsky, Vin Tangpricha, \\ Krista L Spada, Ashley Britt, Bradley Saul, Nathan Gotman, Jessie Wang, Jose Serrano, Subra Kugathasan, Thomas Walters, Lee A Denson
}

\section{Summary}

Background Previous retrospective studies of paediatric ulcerative colitis have had limited ability to describe disease progression and identify predictors of treatment response. In this study, we aimed to identify characteristics associated with outcomes following standardised therapy after initial diagnosis.

Methods The PROTECT multicentre inception cohort study was based at 29 centres in the USA and Canada and included paediatric patients aged 4-17 years who were newly diagnosed with ulcerative colitis. Guided by the Pediatric Ulcerative Colitis Activity Index (PUCAI), patients received initial standardised treatment with mesalazine (PUCAI 10-30) oral corticosteroids (PUCAI 35-60), or intravenous corticosteroids (PUCAI $\geq 65$ ). The key outcomes for this analysis were week 12 corticosteroid-free remission, defined as PUCAI less than 10 and taking only mesalazine, and treatment escalation during the 12 study weeks to anti-tumour necrosis factor $\alpha$ (TNF $\alpha$ ) agents, immunomodulators, or colectomy among those initially treated with intravenous corticosteroids. We identified independent predictors of outcome through multivariable logistic regression using a per-protocol approach. This study is registered with ClinicalTrials.gov, number NCT01536535.

Findings Patients were recruited between July 10, 2012, and April 21, 2015. 428 children initiated mesalazine (n=136), ora corticosteroids $(n=144)$, or intravenous corticosteroids $(n=148)$. Initial mean PUCAI was $31 \cdot 1$ (SD 13.3) in children initiating with mesalazine, $50.4(13.8)$ in those initiating oral corticosteroids, and $66.9(13.7)$ in those initiating intravenous corticosteroids ( $<<0.0001$ for between-group comparison). Week 12 outcome data were available for 132 patients who initiated with mesalazine, 141 with oral corticosteroids, and 143 with intravenous corticosteroids. Corticosteroid-free remission with the patient receiving mesalazine treatment only at 12 weeks was achieved by 64 (48\%) patients in the mesalazine group, 47 (33\%) in the oral corticosteroid group, and 30 (21\%) in the intravenous corticosteroid group $(\mathrm{p}<0.0001)$. Treatment escalation was required by nine $(7 \%)$ patients in the mesalazine group, $21(15 \%)$ in the oral corticosteroid group, and $52(36 \%)$ in the intravenous corticosteroid group $(\mathrm{p}<0.0001)$. Eight patients, all of whom were initially treated with intravenous corticosteroids, underwent colectomy. Predictors of week 12 corticosteroid-free remission were baseline PUCAI less than 35 (odds ratio 2.44, 95\% CI 1.41-4.22; p=0 0015), higher baseline albumin by $1 \mathrm{~g} / \mathrm{dL}$ increments among children younger than 12 years $(4.05,1.90-8 \cdot 64 ; p=0.00030)$, and week 4 remission $(6 \cdot 26$, 3.79-10.35; $\mathrm{p}<0.0001$ ). Predictors of treatment escalation by week 12 in patients initially treated with intravenous corticosteroids included baseline total Mayo score of 11 or higher $(2 \cdot 59,0 \cdot 93-7 \cdot 21 ; \mathrm{p}=0 \cdot 068$ [retained in model due to clinical relevance]), rectal biopsy eosinophil count less than or equal to 32 cells per high power field $(4 \cdot 55,1 \cdot 62-12 \cdot 78$; $\mathrm{p}=0.0040)$, rectal biopsy surface villiform changes $(3 \cdot 05,1 \cdot 09-8 \cdot 56 ; \mathrm{p}=0.034)$, and not achieving week 4 remission $(30 \cdot 28,6 \cdot 36-144 \cdot 20 ; \mathrm{p}<0 \cdot 0001)$.

Interpretation Our findings provide guidelines to assess the response of children newly diagnosed with ulcerative colitis to standardised initial therapy and identify predictors of treatment response and failure. These data suggest that additional therapeutic interventions might be warranted to improve early outcomes, especially in patients presenting with severe disease and requiring intravenous corticosteroids.

Funding National Institutes of Health.

\section{Introduction}

Paediatric ulcerative colitis is markedly heterogeneous with respect to age of onset, anatomical extent, and disease course, with some patients quickly and continually responding to initial therapies, others having intermittent periods of clinical remission and disease flare, and a small number being refractory to current therapies and requiring colectomy. ${ }^{1,2}$ Because of the absence of rigorous clinical trial data in children, the ideal initial treatment frameworks are poorly defined. Previous natural history studies are
Lancet Gastroenterol Hepatol 2017; 2: 855-68 Published Online September 19, 2017 http://dx.doi.org/10.1016/ S2468-1253(17)30252-2 See Comment page 838 Division of Digestive Diseases, Hepatology, and Nutrition, Connecticut Children's Medical Center, Hartford, CT, USA (ProfJ S Hyams MD, K L Spada BS); Collaborative Studies Coordinating Center, University of North Carolina, Chapel Hill, NC, USA (S Davis DrPH, A Marquis MStat, A Britt MPA, B Saul MS, N Gotman MS, J Wang MS); Division of Gastroenterology, Hepatology \& Nutrition, Children's Hospital of East Ontario, Ottawa, ON, Canada (Prof D R Mack MD); Gastroenterology \& Hepatology \& Nutrition, Nationwide Children's Hospital, Columbus, OH, USA (B Boyle MD); Gastroenterology, Hepatology and Nutrition, Hospital For Sick Children, Toronto, ON, Canada (Prof A M Griffiths MD, TWalters MD); Division of Pediatric Gastroenterology, Nutrition \& Liver Diseases, Hasbro Children's Hospital, Providence, RI, USA (Prof N S LeLeiko MD); Division of Pediatric Gastroenterology, Emory University, Atlanta, GA, USA (C G Sauer MD, SVenkateswaran $\mathrm{PhD}$, Prof VTangpricha MD Prof S Kugathasan MD); Division of Pediatric Gastroenterology, Hepatology and Nutrition, Children's Hospital of Pittsburgh, Pittsburgh, PA, USA (Prof D J Keljo MD); Division of Pediatric Gastroenterology, Cohen Children's Medical Center of New York, New Hyde Park, NY, USA (Prof J Markowitz MD); 
Gastroenterology (Digestive Diseases and Nutrition), Women \& Children's Hospital of Buffalo WCHOB, Buffalo, NY, USA (Prof S S Baker MD);

Pediatric Gastroenterology and Nutrition, Goryeb Children's Hospital-Atlantic Health, Morristown, NJ, USA (Prof J Rosh MD); Division of Gastroenterology, Hepatology and Nutrition, The Children's Hospital of Philadelphia, Philadelphia, PA, USA (Prof R N Baldassano MD); Pediatric Gastroenterology, UT Southwestern, Dallas, TX, USA (A Patel MD); Pediatric Gastroenterology, Hepatology and Nutrition, Riley Children's Hospital Indiana, Indianapolis,

IN, USA (M Pfefferkorn MD);

Division of Gastroenterology and Nutrition, IWK Health Centre, Halifax, NS, Canada (Prof A Otley MD); Division of Pediatric Gastroenterology, Hepatology and Nutrition, University of California at San Francisco, San Francisco, CA, USA (Prof M Heyman MD); Division of Gastroenterology and Hepatology, Medical College of Wisconsin, Milwaukee, WI, USA (J Noe MD); Pediatric Gastroenterology, Hepatology and Nutrition, Johns Hopkins Children's Center, Baltimore, MD, USA

(Prof M Oliva-Hemker MD); Gastroenterology, Hepatology and Nutrition, HarvardChildren's Hospital Boston, Boston, MA, USA (P Rufo MD); Gastroenterology, Hepatology \& Nutrition, Ann \& Robert H

Lurie Children's Hospital of

Chicago, Chicago, IL, USA (J Strople MD); Division of Digestive Diseases and Nutrition, UCLA Medical Center, Los Angeles, CA, USA (D Ziring MD); Pediatric Gastroenterology, Hepatology, Nutrition, Primary Children's Medical Center University of Utah, Salt Lake City, UT, USA (Prof S L Guthery MD); Division of Gastroenterology

Hepatology and Nutrition,

University of Minnesota

Medical Center, Minneapolis, MN, USA (B Sudel MD); Division of Pediatric Gastroenterology,

Mt Sinai Hospital, New York City, NY, USA (K Benkov MD, Prof M Dubinsky MD); Division of Pediatric Gastroenterology,

SUNY Upstate Medical University, Syracuse, NY, USA

\section{Research in context}

\section{Evidence before this study}

Because of insufficient paediatric clinical trial data, the selection of initial therapy for children newly diagnosed with ulcerative colitis is largely based on clinical trial data and uncontrolled experiences in adults, and uncontrolled retrospective data in children. We searched PubMed with the MeSH terms "ulcerative colitis", "corticosteroids", "5-aminosalicylates", "treatment", and "outcomes" for studies published in English before Dec 31, 2016. We identified no systematic prospective studies of initial standardised therapy in treatment-naive children. This absence of information has led to imprecision in guidance for clinicians, as well as patients and their families, as to what to expect and when following initiation of 5 -aminosalicylates and corticosteroids in children. Parameters to help establish choices and timings of additional medical therapy such as immunomodulators or biological drugs, with their attendant risks and costs, are currently lacking.

\section{Added value of this study}

We established important reference data on initial response to oral mesalazine, oral corticosteroids, and intravenous corticosteroids. We showed that only $34 \%$ of all patients achieved the ideal 12 week outcome of corticosteroid-free remission with mesalazine treatment only, ranging from $48 \%$ of children presenting with mild-to-moderate disease who were treated initially with mesalazine, to $33 \%$ with

moderate-to-severe disease treated initially with oral corticosteroids, and $21 \%$ in children with severe disease who were admitted to hospital and treated with intravenous

limited in value because of their retrospective nature and largely non-standardised treatment approaches to new-onset disease. Evidence from a multicentre, uncontrolled retrospective study suggested that initial response to therapy could be an important predictive factor of long-term outcome. ${ }^{3}$ Previous research has identified initial endoscopic and clinical disease severity, disease extent, hypalbuminaemia, histopathology, and certain genetic polymorphisms as relevant markers of disease course. ${ }^{3-10}$ However, these studies have been hampered by the patient outcome being characterised without standardised treatment protocols and have largely focused on patients admitted to hospital with severe disease treated with intravenous corticosteroids.

The Predicting Response to Standardized Pediatric Colitis Therapy (PROTECT) study was initiated in 2012 to systematically examine the responses of children and adolescents who were newly diagnosed with ulcerative colitis to consensus-defined disease-severity-based treatment regimens of mesalazine and corticosteroids, with uniform pretherapy criteria established to determine when escalation to additional therapy was required. We aimed to identify rates and predictors of week 52 corticosteroid-free remission with mesalazine maintenance therapy only after initial treatment with mesalazine or corticosteroids. corticosteroids. The need for biological therapy and even colectomy by 12 weeks after diagnosis was largely confined to patients presenting with more severe disease requiring intravenous corticosteroids as their first therapy. The strongest predictor of corticosteroid-free remission by week 12 without the need for additional therapy was clinical remission at week 4, irrespective of corticosteroid status. Commonly measured baseline characteristics such as disease extent, relative rectal sparing, total Mayo score, and serum albumin were important factors in predictive models of early outcomes. Our data also show that characterisation of the extent of eosinophilic infiltrate and the architectural abnormality of surface villiform changes in the initial rectal biopsy also contributed substantially to our predictive models.

\section{Implications of all the available evidence}

Our study adds to the understanding of early clinical outcomes in ulcerative colitis in children and provides crucial information on what clinicians, patients, and families can expect following the start of current standard-of-care therapy in this population. Our modelling identified commonly obtained clinical and laboratory parameters that can be helpful in predicting disease course and can help to guide clinicians in choosing whether or not to add medical therapy beyond 5-aminosalicylates and corticosteroids early in the treatment period. Our data establish standards that can be used for comparisons of effectiveness with newly emerging therapies with higher costs and unknown risks and to determine the usefulness of additional genomic and microbial biomarkers for treatment response.

Because crucial management decisions are often needed at, or shortly after, the time of diagnosis in children with moderate-to-severe ulcerative colitis, we focused this analysis on the early outcome of week 12 corticosteroidfree remission. An improved understanding of the likelihood and predictors of standardised therapy could better inform initial treatment choices.

\section{Methods \\ Study design and participants}

PROTECT was a multicentre inception cohort study based at 29 centres in the USA and Canada. Informed consent or assent was obtained (written assent for children aged 9-17 years) in all cases and the study was approved by the local investigational review board at all investigative sites. The study protocol is available online.

Patients were recruited between July 10, 2012, and April 21, 2015 (appendix p 3). Children aged 4-17 years with a clinical history consistent with colonic inflammation (any combination of diarrhoea, bleeding, and abdominal pain) were eligible for study. Complete demographic, clinical, laboratory, and serological data were obtained, along with stool samples and diagnostic ileocolonoscopy and oesophagogastroduodenoscopy with rectal biopsies. Eligibility criteria were disease extent 
beyond the rectum (ie, proctitis excluded), a baseline Pediatric Ulcerative Colitis Activity Index (PUCAI) ${ }^{11}$ score of at least 10, no previous therapy for colitis, and stool culture negative for enteric bacterial pathogens (Salmonella, Shigella, Campylobacter, Escherichia coli 0157:H7) and Clostridium difficile to xin. A cl inical, endoscopic, and histological diagnosis of ulcerative colitis was made in accordance with previously established criteria. ${ }^{12}$ Note was taken of whether there was patchiness to the endoscopic appearance or relative rectal sparing (rectum macroscopically less involved than more proximal segments). When feasible, baseline colonoscopy was completed to the caecum and the terminal ileum was intubated. Exclusion criteria were clinical, endoscopic, radiological, or histological evidence of Crohn's disease at any time with a minimum of 1 year follow-up, granuloma on any biopsies, use of any oral corticosteroid medications for non-gastrointestinal indications in the past 4 weeks, and other gastrointestinal or non-gastrointestinal disorders that would have interfered with the study-mandated therapeutic framework. Macroscopic or microscopic gastritis was not deemed to indicate Crohn's disease unless deep ulcers or granuloma were present.

\section{Procedures}

Disease extent was classified as proctosigmoiditis, left-sided colitis (to the splenic flexure), extensive colitis (to the hepatic flexure), or pancolitis (beyond the hepatic flexure) by visual evidence. Patients with severe or fulminant disease at presentation who received a flexible sigmoidoscopy because of safety concerns were assigned to the extensive colitis group.

Clinical activity at diagnosis was established with the PUCAI $^{11}$ (range $0-85$, in increments of 5 points) and Mayo score (range 0-12). ${ }^{13}$ A PUCAI less than 10 denoted inactive disease or remission, 10-30 denoted mild disease, 35-60 denoted moderate disease, and 65 or higher denoted severe disease. The site endoscopist assigned a Mayo endoscopic subscore (range 0-3) using standardised photographs that had been distributed to all investigative sites.

A central pathologist (MHC) blinded to clinical data examined a single rectal biopsy from each patient and assessed histological features of chronicity and quantitated acute inflammation by the presence and extent of cryptitis, crypt abscesses, or both. Chronicity was assessed by the presence or absence of any one of mucin depletion, crypt distortion, crypt branching, crypt atrophy, and basal lymphocytosis. Paneth cell metaplasia, surface villiform changes, or basal lymphoid aggregates were recorded if present. The description of eosinophilic inflammation included the peak number of eosinophils per high-power field relative to a cut-point ( $>32$ cells per high-power field) derived from a study of normal rectal biopsies in children. ${ }^{14}$

At baseline, laboratory tests were recorded from local site standard-of-care assessments, as available, within
4 weeks before the initial ulcerative colitis treatment and not more than 2 days after the initiation of treatment. The variables assessed were haemoglobin, platelet count, white blood cell count, serum albumin, erythrocyte sedimentation rate, and C-reactive protein (CRP or high-sensitivity CRP [hsCRP]). Plasma albumin was measured at a central laboratory with ELISA (Cell Biolabs, San Diego, CA, USA) for participants with no available local serum value. $25-\mathrm{OH}$ vitamin $\mathrm{D}$ was measured centrally from plasma collected at baseline. ${ }^{15}$ We report observed values of all laboratory studies with the exception of CRP, which we report with respect to the upper limit of normal (ULN) for the local laboratory. Faecal calprotectin ${ }^{16}$ was measured centrally with ELISA (Buhlmann Laboratories, Schönenbuch, Switzerland) from stool samples collected before colonoscopy cleanout or at 2 days or more after colonoscopy, but not more than 3 days after initial ulcerative colitis treatment. Faecal calprotectin less than $250 \mu \mathrm{g} / \mathrm{g}$ was deemed to suggest inactive disease. Faecal osteoprotegerin was measured centrally for a subset of participants who provided stool specimens that were kept cold after passage (continued cold custody) by use of $0 \cdot 01 \%$ polysorbate 20 added to the extraction buffer in accordance with method published previously. ${ }^{17}$

Serological determination of perinuclear anti-neutrophil cytoplasmic antibodies (pANCA), anti-Saccharomyces cerevisiae antibodies (ASCA) IgG, ASCA IgA, anti-CBir1 (anti-flagellin), and anti-outer membrane precursor protein C (anti-OmpC) was done at Cedars-Sinai Hospital (Los Angeles, CA, USA) by use of previously published methods. ${ }^{18}$ A pANCA titre of 100 or more endotoxin units per $\mathrm{mL}(\mathrm{EU} / \mathrm{mL})$ was deemed to represent a high titre.

Depending on initial PUCAI score, patients received initial treatment with either mesalazine (mild disease), oral corticosteroids (moderate disease), or intravenous corticosteroids (severe disease), with treatment choice based on standardised guidelines with some physician discretion allowed (figure 1). The final choice of initial therapy was made by consensus of the treating physician, patient, and family. Guidelines stated that patients starting on mesalazine should have corticosteroids added to their treatment if disease activity did not improve. Patients initiated on oral or intravenous corticosteroids were guided to start mesalazine after 2 weeks of corticosteroids if disease activity was controlled. A detailed description of treatment guidelines, as well as mesalazine dosing tables, standardised corticosteroid tapering schedules, and use of adjunctive medical therapy (eg, rectal therapy) is provided in the appendix (p 5-7). Mesalazine was used under investigational new drug number 111863. Additional medical therapy in the first 12 weeks was defined as the use of an immunomodulator (thiopurine or methotrexate), calcineurin inhibitor (cyclosporin or tacrolimus), or anti-tumour necrosis factor $\alpha$ (TNF $\alpha)$ agent. The following guidelines were used to help to establish the need for additional medical therapy: disease refractory to intravenous
(P Wali MD); Division of Gastroenterology, Hepatology, and Nutrition, Monroe Carell Jr Children's Hospital of Vanderbilt, Nashville, TN, USA (D Moulton MD); Division of Pediatric Gastroenterology and Nutrition Nemours Children's Clinic, Jacksonville, FL, USA (J Evans MD); Division of Pediatric Gastroenterology, University of North Carolina at Chapel Hill, Chapel Hill, NC, USA (M D Kappelman MD, Prof F A Sylvester MD); Division of Gastroenterology,

Hepatology and Nutrition, Cincinnati Children's Hospital Medical Center, Cincinnati, $\mathrm{OH}$, USA (Prof M H Collins MD, Prof LA Denson MD); and National Institutes of Diabetes, Digestive and Kidney Diseases, Bethesda, MD, USA (J Serrano MD)

Correspondence to: Prof Jeffrey S Hyams MD, Division of Digestive Diseases, Hepatology, and Nutrition, Connecticut Children's Medical Center, Hartford, CT 06106, USA jhyams@connecticutchildrens. org

For the study protocol see http://www.cscc.unc.edu/ protect/AboutUs.php?pg=6 See Online for appendix 


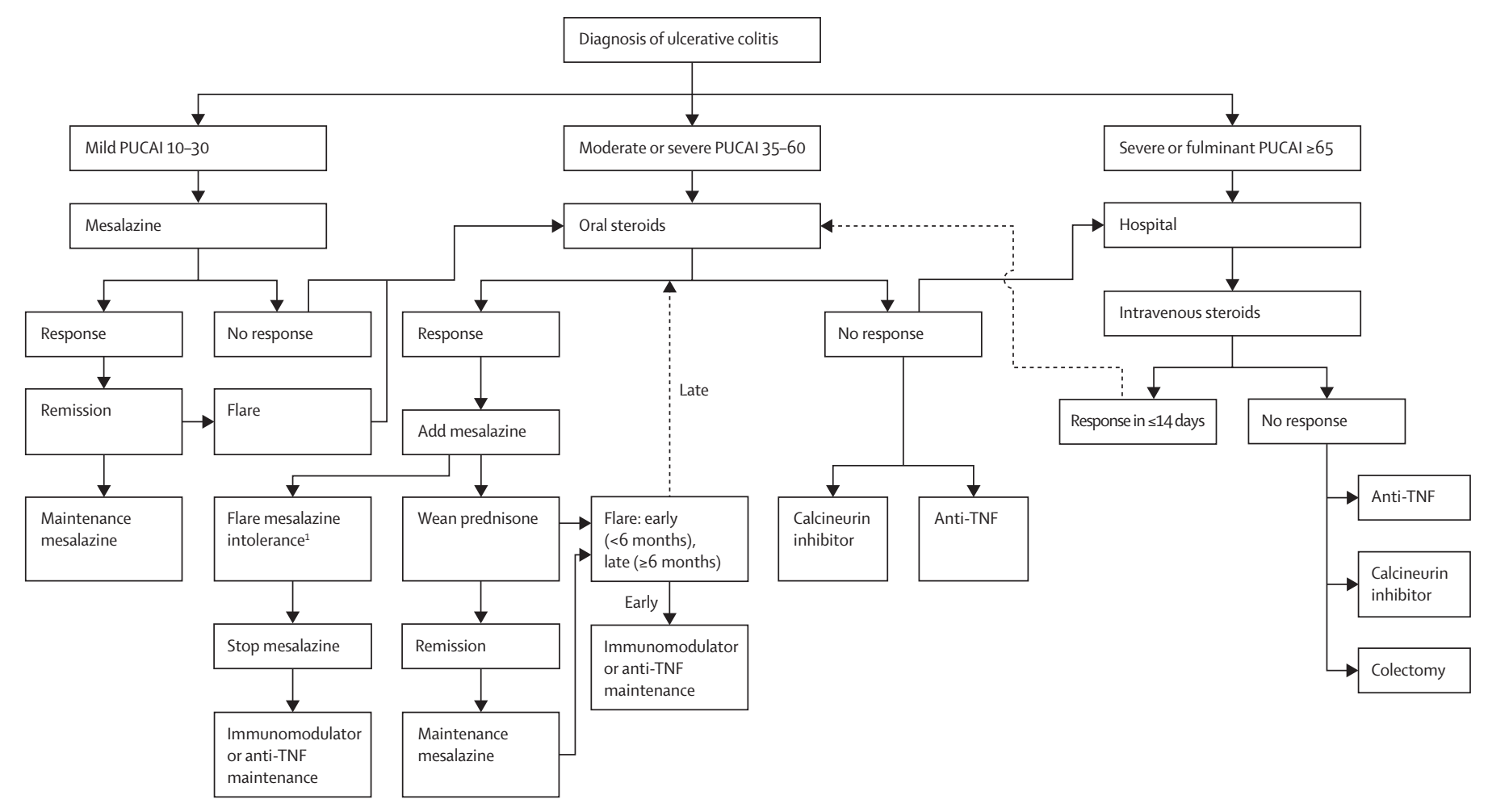

Figure 1: Standardised study treatment guidelines

PUCAI=Pediatric Ulcerative Colitis Activity Index. TNF=tumour necrosis factor.

corticosteroids within the first 14 days per physician discretion to enable the rapid step-up of therapy when needed for severely ill patients; no response to oral corticosteroids within 4 weeks of starting therapy; PUCAI that continued to be 35 or higher despite a minimum of 2-4 weeks of at least $1 \mathrm{mg} / \mathrm{kg}$ per day of prednisone; failure to wean prednisone to below $0.5 \mathrm{mg} / \mathrm{kg}$ per day by week 6; absence of sustained response or remission with use of mesalazine as a maintenance agent; or an adverse reaction to mesalazine preventing its use as a maintenance agent. Intolerance to mesalazine (paradoxical disease worsening, pancreatitis, hepatitis, or other significant side-effects) that precluded its use as a maintenance agent constituted a treatment failure and prompted the use of additional medical therapy. The choice of additional therapy for any patient was at the discretion of the attending physician, irrespective of the reason. If an anti-TNF $\alpha$ agent and immunomodulator were started concomitantly, the anti-TNF $\alpha$ was deemed to be the primary additional therapy. Patients with medically uncontrollable disease underwent colectomy. Rectal therapy was used at the discretion of the clinician and patient. All patients on mesalazine received study-supplied Pentasa (Shire Pharmaceuticals/Pantheon, Greenville, NC, USA).

Participants were enrolled and all baseline assessments were completed before the initiation of therapy.
Minimum follow-up was 1 year, ending in April, 2016 This report focuses on post-baseline assessments during the crucial initial 4 and 12 weeks of treatment after diagnosis, along with interim phone calls, visits, and hospital admissions, as needed. Visit assessments included PUCAI assessment, partial Mayo assessment (excluding the endoscopic subscore), clinical evaluation, and standard-of-care clinical laboratory tests. Stool samples and plasma for specialised laboratory assessments were collected at 4 and 12 weeks. We established visit windows to maximise follow-up observations. Week 4 assessments were made between days 21 and 49 and week 12 assessments occurred between days 60 and 120 .

\section{Outcomes}

The primary outcome of the PROTECT study is week 52 corticosteroid-free remission without the need for additional medical therapy or colectomy, which will be reported at a later date. Given that crucial management decisions are often required at the time of diagnosis in moderately-to-severely ill children we focused this analysis on the early outcome of week 12 corticosteroidfree remission (PUCAI $<10$ ) with patients receiving only mesalazine and no corticosteroids for a minimum of 2 weeks. Other outcomes were week 4 remission, irrespective of corticosteroids, week 12 corticosteroid-free 
remission in patients who had achieved week 4 clinical remission (sustained remission), week 12 corticosteroidfree remission in patients who started on mesalazine and never required any corticosteroids (corticosteroids naive), week 12 corticosteroid-free remission with faecal calprotectin less than $250 \mu \mathrm{g} / \mathrm{g}$, week 12 remission irrespective of corticosteroids, and escalation to additional medical therapy or colectomy at weeks 4 or 12 . Serious adverse events were reviewed by an independent medical monitor. Safety data were reviewed quarterly by a data and safety monitoring board.

\section{Statistical analysis}

Data collection and reporting was done in accordance with the STROBE $^{19}$ and TRIPOD ${ }^{20}$ guidelines for observational studies and the reporting of multivariable prediction models. A planned sample size of 430 patients was calculated to ensure at least $90 \%$ power to identify an odds ratio $(\mathrm{OR})$ of at least 2.5 in predictive modelling, with $\mathrm{p}$ values of less than 0.05 being deemed statistically significant. We compared participant subgroups defined by initial ulcerative colitis treatment (mesalazine, oral corticosteroids, or intravenous corticosteroids) or outcome classification ( remission, a dditional $m$ edical therapy o $r$ colectomy, or neither) for baseline factors and clinical outcomes using a $\chi^{2}$ test or Fisher's exact test for categorical assessments, a Mantel-Haenszel $\chi^{2}$ test for ordinal categorical assessments, a $t$ test for normally distributed continuous assessments, and a Wilcoxon rank-sum test for continuous assessments with skewed distributions. All tests were two-sided. We made no adjustment for multiple comparisons. We did the statistical analyses with SAS version 9.3.

We identified $\mathrm{p}$ redictors o $\mathrm{fc}$ linical o utcomes $\mathrm{i} n$ multivariable logistic regression models of the per-protocol population. Potential predictors for week 4 outcomes included all baseline clinical and laboratory factors, whereas potential predictors of week 12 outcomes included baseline factors, week 4 assessments, and change from baseline to week 4 . We fitted models of week 12 corticosteroid-free remission and week 4 remission for the full cohort of participants and for subgroups based on initial therapy. We also modelled escalation to additional medical therapy or colectomy at weeks 4 and 12 for the subgroup of participants starting on intravenous steroids because that was the group for whom additional intervention was most common. We obtained adjusted ORs and 95\% CIs from logistic regression of a best-fit set of predictors with a cutoff of a $\mathrm{p}$ value less than or equal to 0.06 , which we chose because several consistent predictors had $p$ values that were nominally greater than $0 \cdot 05$. Predictors were identified i $\mathrm{n}$ a $\mathrm{s}$ tepwise $\mathrm{f}$ ashion a nd $\mathrm{r}$ efined th rough clinical review and internal validation to address over-fitting a nd $\mathrm{m}$ issing $\mathrm{d}$ ata $\mathrm{v}$ ia $\mathrm{b}$ ootstrapping a nd multiple imputation, as described in the appendix (pp 7-9). We assessed model fit with the area under curve (AUC) of the receiver operating characteristic (ROC) curve, $R^{2}$ (maximum rescaled; appendix p 8), and Hosmer-Lemenshow goodness of fit test.

Prediction models were affected by the pattern of missing data across assessments. Because of the percentage of missing values for CRP, faecal calprotectin, and faecal osteoprotegerin, we did not include these items in the multivariable models, irrespective of the strength of the unadjusted association, although we did include CRP and faecal calprotectin in the multiple imputation analysis.

This study is registered with ClinicalTrials.gov, NCT01536535, and is closed to new participants.

\section{Role of the funding source}

The funders of the study collaborated with the authors in finalising the study design, provided feedback throughout the period of data collection, and participated in data analysis, data interpretation, and writing of the report. The manuscript was written by the PROTECT Study Publication Committee. All authors had access to the study data and reviewed and approved the final manuscript.

\section{Results}

467 patients enrolled in PROTECT between July 10, 2012, and April 21, 2015 (figure 2). The median enrolment per centre was 13 patients (range 2-47). 36 patients were removed from the study secondary to a change in diagnosis to Crohn's disease $(\mathrm{n}=28)$ or a major protocol inclusion violation (four lacked informed consent, two had inadequate data collection, one had $C$ difficile diagnosis at baseline, and one enrolled 3 weeks after colonoscopy). An additional patient who had a colonic perforation at diagnostic colonoscopy and two patients who refused medical therapy were also excluded, leaving 428 treated patients evaluable for outcome determination. Table 1 shows demographic, clinical, and laboratory characteristics categorised by initial therapy. Mean age was $12 \cdot 7$ years (SD 3.3), $216(50 \%)$ of 428 patients were male, 355 (83\%) patients had extensive disease or pancolitis, and 351 patients $(84 \%$ of 420 patients with data on race) were white. More severe clinical and laboratory features were noted in patients receiving intravenous corticosteroids (initial mean PUCAI 66.9 [SD 13.7]) or oral corticosteroids $(50.4[13.8])$ than in those initially treated with mesalazine $(31 \cdot 1[13 \cdot 3]$; $\mathrm{p}<0 \cdot 0001)$.

Missing data for initial standard-of-care laboratory values ranged from six (1\%) of 428 patients for albumin, to $43(10 \%)$ patients for erythrocyte sedimentation rate across other baseline laboratory markers, with the exception of CRP, for which data was missing from $113(26 \%)$ patients. Initial stool assessments were missing from 189 (44\%) patients for faecal calprotectin and 250 (58\%) patients for osteoprotegerin. Week 4 stool assessments and standard-of-care blood laboratory assessments had more missing data. At baseline, data 


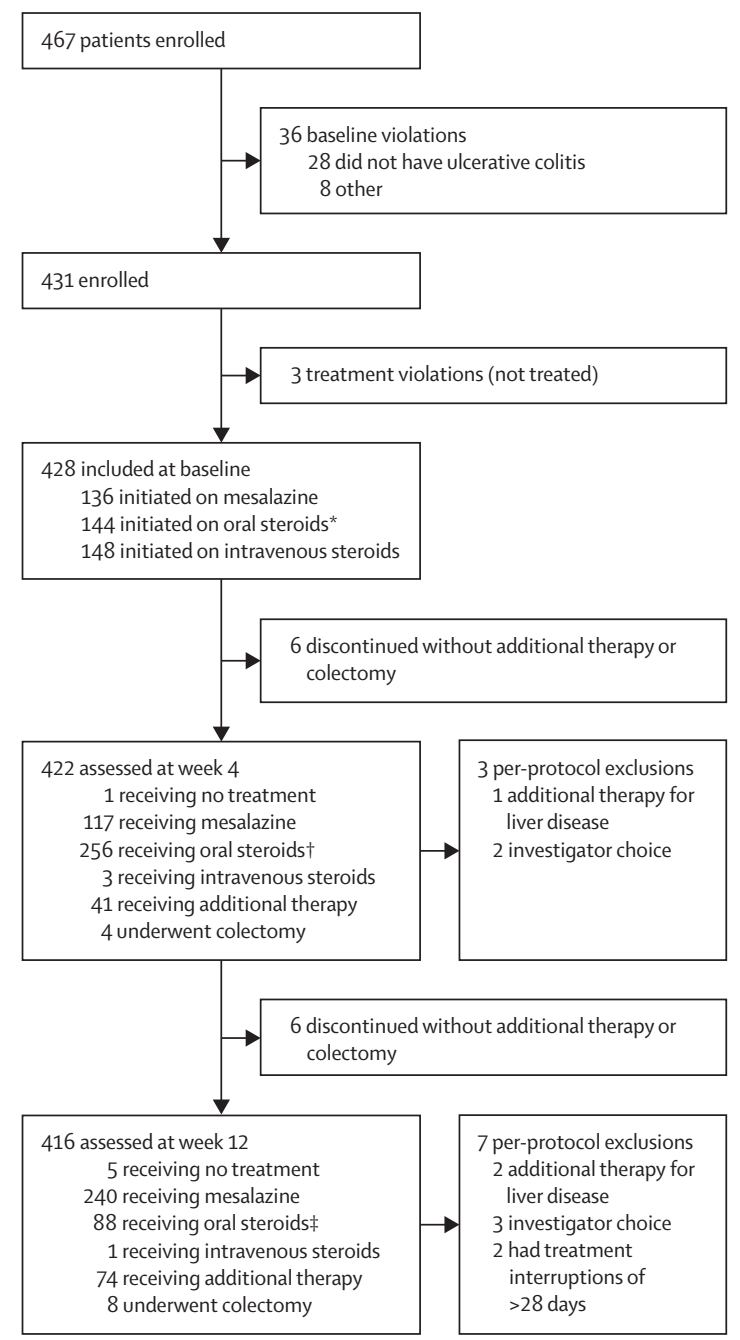

Figure 2: Trial profile

* Includes three patients who received both oral corticosteroids and mesalazine and one patient who received intravenous corticosteroids for 1 day without being admitted to hospital. †Includes 233 patients on both oral corticosteroids and mesalazine. łIncludes 80 patients on both oral corticosteroids and mesalazine.

were missing from 61 (14\%) patients for histology, 31 (7\%) patients for serology, and $35(8 \%)$ patients for vitamin D. Standard-of-care laboratory tests seemed to be more complete for participants with more severe disease. All participants had complete data for baseline PUCAI, Mayo score, and endoscopy assessments.

Outcome data were available for 422 (99\%) of 428 patients at week 4 and 416 (97\%) patients at week 12 . Average assessment times were at $4 \cdot 1$ weeks (SD 0.6; 340 [82\%] of 415 patients within days 25-34) and $12 \cdot 2$ weeks $(1 \cdot 3 ; 331$ [82\%] of 403 patients within days 75-96). Patients who escalated to additional therapy (and therefore had a defined outcome), but subsequently discontinued the study did not attend the week 4 visit $(n=7)$ or the week 12 visit $(n=13)$. Seven participants (three by week 4 and four between weeks 4 and 12) were excluded from the predictive modelling because of treatment violations, including gaps in treatment of longer than 28 days (two patients) and escalation to additional therapy due to liver disease (two patients) or because of investigator choice without meeting a guideline specified by the standardised treatment algorithm (three patients).

$286(67 \%)$ of all 428 patients received the initial therapy indicated by the standardised PUCAI-based treatment framework, including 84 (82\%) of 102 patients with PUCAI of 10-30 who received mesalazine, 96 (52\%) of 185 patients with PUCAI of 35-60 who received oral corticosteroids, and 106 (75\%) of 141 patients with PUCAI of 65 or higher who received intravenous corticosteroids. Overall, 136 patients received mesalazine (mean initial therapy dose $67 \mathrm{mg} / \mathrm{kg}$ per day [SD 9]), 144 patients received oral corticosteroids (mean $0.9 \mathrm{mg} / \mathrm{kg}$ per day [0.3]), and 148 patients received intravenous corticosteroids (mean $1.0 \mathrm{mg} / \mathrm{kg}$ per day [0.4]). Rectal therapy (corticosteroid or mesalazine) was given at baseline to 12 (3\%) patients, irrespective of other therapies. This number increased by week 4 , when $25(6 \%)$ of 422 patients had received rectal mesalazine and $22(5 \%)$ patients had received rectal corticosteroids, and increased further by week 12, when $45(11 \%)$ of 416 patients had received rectal mesalazine and 29 (7\%) had received rectal corticosteroids, before use of any additional medical therapies.

By week 12, 376 (90\%) of 416 participants had received mesalazine at some point and 310 (75\%) had received mesalazine therapy for at least 8 weeks. At week 12, mesalazine was being used by 320 (77\%) patients either alone $(240$ [58\%] patients) or in conjunction with oral corticosteroids (80 [19\%] patients). Mesalazine was discontinued in $29(7 \%)$ patients because of intolerance or side-effects in 12 (3\%) patients (one moderate rash, one mild rash, and 10 worsening of symptoms), ineffectiveness in 15 (4\%) patients, and the patient's choice in two $(<1 \%)$ patients. Treatment-emergent adverse events before escalation of therapy beyond mesalazine or corticosteroids are shown in the appendix (p 25).

Figure 3 shows the main clinical outcomes for all enrolled patients by initial therapy. Week 4 remission occurred in 73 (54\%) of 135 patients who initially started on mesalazine, 81 (57\%) of 143 patients who initially started on oral corticosteroids, and 57 (40\%) of 148 patients who initially started on intravenous corticosteroids ( $\mathrm{p}=0.0079 ;$ table 2$)$. By week 12 , corticosteroid-free remission was seen in 64 (48\%) of 132 patients in the mesalazine group, 47 (33\%) of 141 patients in the oral corticosteroid group, and $30(21 \%)$ of 143 patients in the intravenous corticosteroid group $(\mathrm{p}<0 \cdot 0001)$. Among the patients initiating the medication specified by the PUCAI-based standardised guideline, corticosteroid-free remission at week 12 was seen in 


\begin{tabular}{|c|c|c|c|c|c|}
\hline & $\begin{array}{l}\text { Total } \\
(n=428)\end{array}$ & $\begin{array}{l}\text { Mesalazine } \\
(n=136)\end{array}$ & $\begin{array}{l}\text { Oral corticosteroids } \\
(\mathrm{n}=144)\end{array}$ & $\begin{array}{l}\text { Intravenous } \\
\text { corticosteroids } \\
(n=148)\end{array}$ & p value \\
\hline Age (years) & $12 \cdot 7(3 \cdot 3)$ & $12 \cdot 8(3 \cdot 3)$ & $12 \cdot 5(3 \cdot 3)$ & $12 \cdot 7(3 \cdot 2)$ & 0.73 \\
\hline$\geq 12$ years & $289(68 \%)$ & $92(68 \%)$ & $96(67 \%)$ & $101(68 \%)$ & .. \\
\hline Sex & & & & & 0.079 \\
\hline Girls & $212(50 \%)$ & $69(51 \%)$ & $61(42 \%)$ & $82(55 \%)$ & .. \\
\hline Boys & $216(50 \%)$ & $67(49 \%)$ & $83(58 \%)$ & $66(45 \%)$ &. \\
\hline \multicolumn{6}{|l|}{ Race or ethnicity } \\
\hline White & $351 / 420(84 \%)$ & $113 / 134(84 \%)$ & $122 / 140(87 \%)$ & $116 / 146(79 \%)$ &.. \\
\hline Non-white & $69 / 420(16 \%)$ & $21 / 134(16 \%)$ & $18 / 140(13 \%)$ & $30 / 146(21 \%)$ & 0.21 \\
\hline Hispanic or Latino & $38 / 424(9 \%)$ & $18 / 134(13 \%)$ & $9 / 143(6 \%)$ & $11 / 147(7 \%)$ & 0.085 \\
\hline \multicolumn{6}{|l|}{ Z score } \\
\hline Weight & $-0 \cdot 1(1 \cdot 2)$ & $0.0(1.1)$ & $0.0(1.2)$ & $-0.3(1 \cdot 2)$ & 0.037 \\
\hline Height & $0.1(1.0)$ & $0.1(1.0)$ & $0.2(0.9)$ & $-0.0(1.0)$ & 0.052 \\
\hline Body-mass index & $-0 \cdot 2(1 \cdot 3)$ & $-0.0(1 \cdot 2)$ & $-0 \cdot 2(1 \cdot 3)$ & $-0.4(1.4)$ & 0.035 \\
\hline Admitted to hospital at baseline & $166(39 \%)$ & $4(3 \%)$ & $14(10 \%)$ & $148(100 \%)$ & $<0.0001$ \\
\hline Disease extent & & & & & $<0.0001$ \\
\hline Proctosigmoiditis & $29(7 \%)$ & $22(16 \%)$ & $4(3 \%)$ & $3(2 \%)$ &. \\
\hline Left-sided colitis & $44(10 \%)$ & $28(21 \%)$ & $14(10 \%)$ & $2(1 \%)$ & \\
\hline $\begin{array}{l}\text { Extensive, pancolitis, or } \\
\text { unassessable* }\end{array}$ & $355(83 \%)$ & $86(63 \%)$ & $126(88 \%)$ & $143(97 \%)$ & \\
\hline $\begin{array}{l}\text { Total PUCAI (range } 0-85 \text { in increments } \\
\text { of 5) }\end{array}$ & $50 \cdot 0(19 \cdot 9)$ & $31 \cdot 1(13 \cdot 3)$ & $50 \cdot 4(13 \cdot 8)$ & $66.9(13.7)$ & $<0.0001$ \\
\hline 10-30 (mild) & $102(24 \%)$ & $84(62 \%)$ & $15(10 \%)$ & $3(2 \%)$ & \\
\hline 35-60 (moderate) & $185(43 \%)$ & $50(37 \%)$ & $96(67 \%)$ & $39(26 \%)$ & .. \\
\hline$\geq 65$ (severe) & $141(33 \%)$ & $2(1 \%)$ & $33(23 \%)$ & $106(72 \%)$ & \\
\hline Abdominal pain & $354(83 \%)$ & $97(71 \%)$ & $122(85 \%)$ & $135(91 \%)$ & $<0.0001$ \\
\hline Diarrhoea & $393(92 \%)$ & $104(76 \%)$ & $142(99 \%)$ & $147(99 \%)$ & $<0.0001$ \\
\hline Rectal bleeding & $398(93 \%)$ & $117(86 \%)$ & $136(94 \%)$ & $145(98 \%)$ & $<0.0001$ \\
\hline Total Mayo score (0-12) & $7.8(2.5)$ & $5 \cdot 5(1.8)$ & $7.9(1.7)$ & $9 \cdot 8(1 \cdot 7)$ & $<0.0001$ \\
\hline $0-6$ & $125(29 \%)$ & $99(73 \%)$ & $23(16 \%)$ & $3(2 \%)$ & \\
\hline 7-9 & $183(43 \%)$ & $35(26 \%)$ & $93(65 \%)$ & $55(37 \%)$ & .. \\
\hline$\geq 10$ & $120(28 \%)$ & $2(1 \%)$ & $28(19 \%)$ & $90(61 \%)$ & .. \\
\hline$\geq 11$ & $71(17 \%)$ & 0 & $6(4 \%)$ & $65(44 \%)$ & $<0.0001$ \\
\hline Mayo endoscopic subscore (0-3) & $2 \cdot 2(0 \cdot 7)$ & $1.8(0.6)$ & $2 \cdot 2(0.6)$ & $2.6(0.5)$ & $<0.0001$ \\
\hline 1 & $59(14 \%)$ & $43(32 \%)$ & $13(9 \%)$ & $3(2 \%)$ &. \\
\hline 2 & $224(52 \%)$ & $79(58 \%)$ & $88(61 \%)$ & $57(39 \%)$ &. \\
\hline 3 & $145(34 \%)$ & $14(10 \%)$ & $43(30 \%)$ & $88(59 \%)$ &.. \\
\hline Relative rectal sparing & $38 / 427(9 \%)$ & $17 / 136(13 \%)$ & $15 / 144(10 \%)$ & $6 / 147(4 \%)$ & 0.034 \\
\hline Macroscopic patchiness & $37 / 427(9 \%)$ & $23 / 136(17 \%)$ & $8 / 144(6 \%)$ & $6 / 147(4 \%)$ & 0.00017 \\
\hline Cecal patch & $29 / 397(7 \%)$ & $17 / 135(13 \%)$ & $10 / 136(7 \%)$ & $2 / 126(2 \%)$ & 0.0029 \\
\hline Non-specific macroscopic gastritis & $114 / 420(27 \%)$ & $33 / 131(25 \%)$ & $28 / 143(20 \%)$ & $53 / 146(36 \%)$ & 0.0050 \\
\hline Microscopic gastritis & $242 / 418(58 \%)$ & $59 / 129(46 \%)$ & $86 / 142(61 \%)$ & $97 / 147(66 \%)$ & 0.0023 \\
\hline $\begin{array}{l}\text { Rectal biopsy eosinophilic inflammation } \\
\text { ( }>32 \text { cells per high-power field) }\end{array}$ & $210 / 367(57 \%)$ & $64 / 116(55 \%)$ & $82 / 125(66 \%)$ & $64 / 126(51 \%)$ & 0.052 \\
\hline Rectal biopsy surface villiform changes & $135 / 364(37 \%)$ & $31 / 115(27 \%)$ & $47 / 125(38 \%)$ & $57 / 124(46 \%)$ & 0.010 \\
\hline Rectal biopsy basal plasmacytosis & $176 / 336(52 \%)$ & $51 / 111(46 \%)$ & $65 / 118(55 \%)$ & $60 / 107(56 \%)$ & 0.25 \\
\hline Haemoglobin (g/dL) & $11 \cdot 4(2 \cdot 2)$ & $12.5(1.8)$ & $11 \cdot 5(2 \cdot 1)$ & $10 \cdot 5(2 \cdot 2)$ & $<0.0001$ \\
\hline$<10$ & $98 / 402(24 \%)$ & $8 / 122(7 \%)$ & $28 / 133(21 \%)$ & $62 / 148(42 \%)$ &.. \\
\hline$<12$ & $231 / 402(57 \%)$ & $46 / 122(38 \%)$ & $77 / 133(58 \%)$ & $108 / 148(73 \%)$ & .. \\
\hline Platelet count $\left(\times 10^{9}\right.$ cells per $\left.\mathrm{L}\right)$ & $372(303-462)$ & $319(251-406)$ & $376(318-464)$ & $411(339-509)$ & $<0.0001$ \\
\hline$>500$ & $77 / 399(19 \%)$ & $10 / 121(8 \%)$ & $28 / 133(21 \%)$ & $39 / 145(27 \%)$ & 0.00053 \\
\hline
\end{tabular}




\begin{tabular}{|c|c|c|c|c|c|}
\hline & $\begin{array}{l}\text { Total } \\
(n=428)\end{array}$ & $\begin{array}{l}\text { Mesalazine } \\
(n=136)\end{array}$ & $\begin{array}{l}\text { Oral corticosteroids } \\
(n=144)\end{array}$ & $\begin{array}{l}\text { Intravenous } \\
\text { corticosteroids } \\
(\mathrm{n}=148)\end{array}$ & p value \\
\hline \multicolumn{6}{|l|}{ (Continued from previous page) } \\
\hline White blood count $\left(\times 10^{9}\right.$ cells per $\left.\mathrm{L}\right)$ & $9 \cdot 2(7 \cdot 2-12 \cdot 1)$ & $7 \cdot 8(6 \cdot 5-9 \cdot 3)$ & $9 \cdot 2(7 \cdot 0-11 \cdot 1)$ & $11 \cdot 3(8 \cdot 7-14 \cdot 9)$ & $<0.0001$ \\
\hline$>12$ & $100 / 397(25 \%)$ & $10 / 119(8 \%)$ & 23/133 (17\%) & $67 / 145(46 \%)$ & .. \\
\hline $\begin{array}{l}\text { Erythrocyte sedimentation rate } \\
(\mathrm{mm} / \mathrm{h})\end{array}$ & $25(12-42)$ & $15(8-24)$ & $25(12-39)$ & $38(21-57)$ & $<0.0001$ \\
\hline$\leq 20$ & $165 / 385(43 \%)$ & 79/118 (67\%) & $53 / 125(42 \%)$ & $33 / 142(23 \%)$ &.. \\
\hline$>40$ & $102 / 385(26 \%)$ & $8 / 118(7 \%)$ & 29/125 (23\%) & $65 / 142(46 \%)$ &.. \\
\hline CRP/hsCRP & & & & &.. \\
\hline$>$ ULN & $144 / 315(46 \%)$ & $18 / 89(20 \%)$ & $44 / 102(43 \%)$ & $82 / 124(66 \%)$ & $<0.0001$ \\
\hline$>2 \times U L N$ & $97 / 315(31 \%)$ & 10/89 (11\%) & $27 / 102(26 \%)$ & $60 / 124(48 \%)$ & $<0.0001$ \\
\hline Albumin (g/dL) & $3 \cdot 7(0 \cdot 7)$ & $4 \cdot 0(0 \cdot 7)$ & $3.7(0.6)$ & $3 \cdot 4(0 \cdot 7)$ & $<0.0001$ \\
\hline$<3.5$ & $138 / 422(33 \%)$ & 25/133 (19\%) & $37 / 142(26 \%)$ & $76 / 147(52 \%)$ & .. \\
\hline Faecal calprotectin $(\mu \mathrm{g} / \mathrm{g}) \dagger$ & $2352(1202-3928)$ & $1692(851-3631)$ & $2663(1202-3664)$ & $3202(1495-4384)$ & 0.030 \\
\hline$\geq 250$ & $226 / 239(95 \%)$ & $64 / 74(86 \%)$ & 73/75 (97\%) & $89 / 90(99 \%)$ &.. \\
\hline Faecal osteoprotegerin $(\mathrm{pg} / \mathrm{mL}) \dagger$ & $424(31-3259)$ & 119 (31-1677) & $318(31-1638)$ & 1491 (169-6830) & 0.0012 \\
\hline$>1000$ & 70/178 (39\%) & $15 / 53(28 \%)$ & $18 / 59(31 \%)$ & $37 / 66(56 \%)$ &.. \\
\hline $25-\mathrm{OH}$ vitamin $\mathrm{D}$ (ng/mL) & $28 \cdot 5(23 \cdot 9-34 \cdot 8)$ & $28 \cdot 1(23 \cdot 8-34 \cdot 0)$ & $29 \cdot 9(25 \cdot 2-36 \cdot 4)$ & $27 \cdot 4(22 \cdot 4-33 \cdot 0)$ & 0.032 \\
\hline$<20$ (deficient) & 42/393 (11\%) & $14 / 125(11 \%)$ & $10 / 132(8 \%)$ & $18 / 136(13 \%)$ &.. \\
\hline \multicolumn{6}{|l|}{ pANCA (EU/mL) } \\
\hline Positive titre & $259 / 397(65 \%)$ & $73 / 125(58 \%)$ & $90 / 135(67 \%)$ & $96 / 137(70 \%)$ & 0.13 \\
\hline$\geq 100$ & 75/397 (19\%) & $17 / 125(14 \%)$ & $28 / 135(21 \%)$ & $30 / 137(22 \%)$ & 0.18 \\
\hline OmpC & $7 \cdot 4(5 \cdot 3-11 \cdot 2)$ & $7 \cdot 2(5 \cdot 1-11 \cdot 2)$ & $7 \cdot 3(5 \cdot 7-10 \cdot 2)$ & $7 \cdot 5(5 \cdot 3-11 \cdot 6)$ & 0.76 \\
\hline Positive titre & $21 / 397(5 \%)$ & $8 / 125(6 \%)$ & $7 / 135(5 \%)$ & 6/137 (4\%) & 0.76 \\
\hline$\geq 12$ & $81 / 397(20 \%)$ & $25 / 125(20 \%)$ & 25/135 (19\%) & $31 / 137(23 \%)$ & 0.70 \\
\hline CBir1-postive titre & 76/397 (19\%) & $27 / 125(22 \%)$ & $27 / 135(20 \%)$ & $22 / 137(16 \%)$ & 0.50 \\
\hline
\end{tabular}

Data are mean (SD), $n(\%), n / N(\%)$, or median (IQR) unless noted otherwise. $n / N$ values show missing data. p values comparing groups are from a $\chi^{2}$ or Fisher's exact test for categorical variables, a Mantel-Haenszel $\chi^{2}$ test for ordinal variables, and ANOVA or Kruskal-Wallis test for continuous variables. PUCAI=Pediatric Ulcerative Colitis Activity Index. $C R P=C$-reactive protein. $U L N=$ upper limit of normal. $E U=$ endotoxin units. $\mathrm{pANCA}=$ perinuclear anti-neutrophil cytoplasmic antibody. OmpC=outer membrane precursor protein C. CBir1=flagellin. *Unassessable represents severe or fulminant disease at presentation and that the clinician did a flexible sigmoidoscopy for safety concerns. †Results limited to stool collected before 4 days of initial treatment, and before or after colonoscopy cleanout.

Table 1: Demographic and clinical characteristics by initial therapy

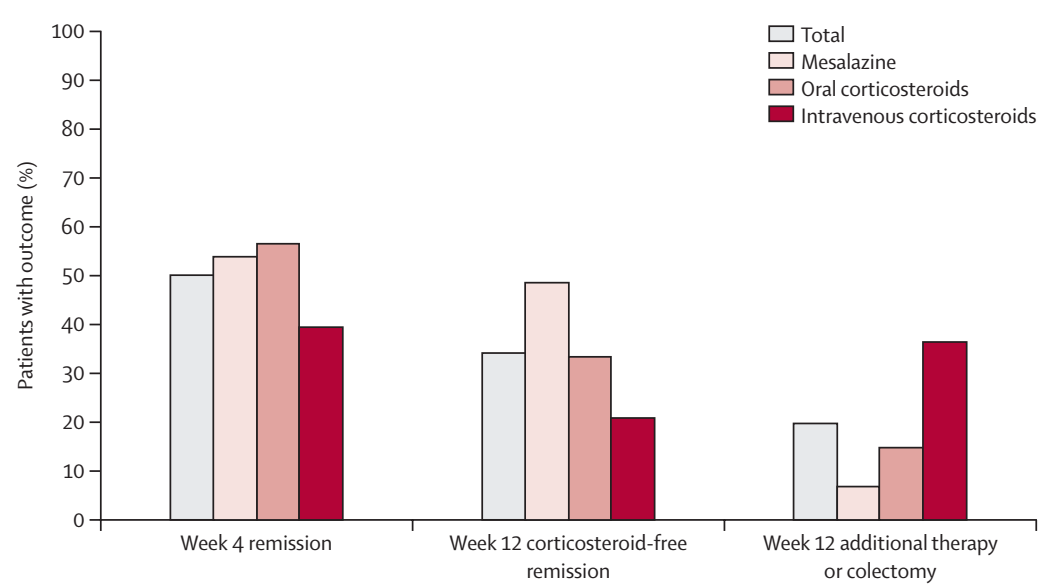

Figure 3: Clinical outcome at Weeks 4 and 12 for the study cohort by initial therapy

$40(49 \%)$ of 82 patients initially treated with mesalazine, $33(34 \%)$ of the 96 treated with oral corticosteroids, and $22(22 \%)$ of the 102 treated with intravenous corticosteroids. In a post-hoc analysis we noted that $85(20 \%)$ of 416 patients had a PUCAI of less than 10 at week 12 but were still on corticosteroids (43 [10\%] patients) or had discontinued corticosteroids less than 2 weeks previously (42 [10\%] patients). In patients still receiving oral corticosteroids at week 12 , the median dose was $0.3 \mathrm{mg} / \mathrm{kg}$ per day (IQR $0 \cdot 19-0 \cdot 51$ ) of prednisone equivalent. One patient was receiving intravenous corticosteroids. Outcome data stratified by whether or not the patient initiated the drug specified by the PUCAI-based standardised guideline are shown in the appendix (p 10).

By week 4, four (3\%) of 143 patients who initiated oral corticosteroids required infliximab and 36 (25\%) of 144 patients who initiated intravenous corticosteroids required infliximab (35 patients; $\mathrm{p}<0.0001)$ or a calcineurin inhibitor (one patient). Immunomodulator monotherapy was started in one (1\%) of 135 patients in the mesalazine group, two (1\%) of 143 patients in the oral corticosteroid group, and $1(1 \%)$ of 144 patients in the intravenous corticosteroid group. Four patients, all 


\begin{tabular}{|c|c|c|c|c|c|}
\hline & $\begin{array}{l}\text { Total } \\
(\mathrm{n}=428)\end{array}$ & $\begin{array}{l}\text { Mesalazine } \\
(n=136)\end{array}$ & $\begin{array}{l}\text { Oral } \\
\text { corticosteroids } \\
(n=144)\end{array}$ & $\begin{array}{l}\text { Intravenous } \\
\text { corticosteroids } \\
(n=148)\end{array}$ & p value \\
\hline \multicolumn{6}{|l|}{ Week 4} \\
\hline Patients assessed for outcomes & $422(99 \%)^{*}$ & $135(99 \%)^{*}$ & $143(99 \%)^{*}$ & $144(97 \%)^{*}$ & .. \\
\hline $\begin{array}{l}\text { Remission } \\
\text { (PUCAI <10 and no additional therapy or colectomy) }\end{array}$ & $211(50 \%)$ & $73(54 \%)$ & $81(57 \%)$ & $57(40 \%)$ & 0.0079 \\
\hline Remission with faecal calprotectin $<250 \mu \mathrm{g} / \mathrm{g} \dagger$ & $56 / 283(20 \%)$ & $17 / 91(19 \%)$ & $26 / 98(27 \%)$ & $13 / 94(14 \%)$ & 0.083 \\
\hline Additional therapy or colectomy & $45(11 \%)$ & $1(1 \%)$ & $6(4 \%)$ & $38(26 \%)$ & $<0.0001$ \\
\hline \multicolumn{6}{|l|}{ First additional therapy } \\
\hline Anti-TNF (with or without other additional therapies) & $39(9 \%)$ & 0 & $4(3 \%)$ & $35(24 \%)$ & $<0.0001$ \\
\hline Calcineurin inhibitor (without other additional therapy) & $1(0 \%)$ & 0 & 0 & $1(1 \%)$ & $1.0 \ddagger$ \\
\hline Immunomodulator (without other additional therapy) & $4(1 \%)$ & $1(1 \%)$ & $2(1 \%)$ & $1(1 \%)$ & $0.84 \ddagger$ \\
\hline Colectomy (with or without other additional therapy) $\S$ & $4(1 \%)$ & 0 & 0 & $4(3 \%)$ & $0.035 \ddagger$ \\
\hline \multicolumn{6}{|l|}{ Week 12} \\
\hline Patients assessed for outcomes & $416(97 \%)^{*}$ & $132(97 \%)^{*}$ & $141(98 \%)^{*}$ & $143(97 \%)^{*}$ & .. \\
\hline Corticosteroid-free remission $\uparrow$ & $141(34 \%)$ & $64(48 \%)$ & $47(33 \%)$ & $30(21 \%)$ & $<0.0001$ \\
\hline $\begin{array}{l}\text { Corticosteroid-naive remission in patients starting } \\
\text { on mesalazine }\end{array}$ & .. & $61(46 \%)$ & .. & .. & .. \\
\hline $\begin{array}{l}\text { Corticosteroid-free remission and faecal calprotectin } \\
<250 \mu \mathrm{g} / \mathrm{g} \dagger\end{array}$ & $56 / 282(20 \%)$ & $25 / 90(28 \%)$ & $17 / 103(17 \%)$ & $14 / 89(16 \%)$ & 0.073 \\
\hline Corticosteroid-free remission and week 4 remission & $109(26 \%)$ & $45(34 \%)$ & $40(28 \%)$ & $24(17 \%)$ & 0.0038 \\
\hline Ever took corticosteroid (subset starting mesalazine) &.. & $35(27 \%)$ & .. & .. & .. \\
\hline $\begin{array}{l}\text { PUCAI }<10 \text { without additional therapy or colectomy } \\
\text { but not corticosteroid-free }\end{array}$ & $85(20 \%)$ & $10(8 \%)$ & $40(28 \%)$ & $35(24 \%)$ & $<0.0001$ \\
\hline Additional therapy or colectomy & $82(20 \%)$ & $9(7 \%)$ & $21(15 \%)$ & $52(36 \%)$ & $<0.0001$ \\
\hline \multicolumn{6}{|l|}{ First additional therapy } \\
\hline Anti-TNF (with or without other additional therapies) & $49(12 \%)$ & $1(1 \%)$ & $10(7 \%)$ & $38(27 \%)$ & $<0 \cdot 0001$ \\
\hline Calcineurin inhibitor (without other additional therapy) & $1(0 \%)$ & 0 & 0 & $1(1 \%)$ & $1.0 \ddagger$ \\
\hline Immunomodulator (without other additional therapy) & $31(7 \%)$ & $8(6 \%)$ & $11(8 \%)$ & $12(8 \%)$ & 0.75 \\
\hline Colectomy (with or without additional therapy) & $8(2 \%)$ & 0 & 0 & $8(6 \%)$ & 0.00041 \\
\hline
\end{tabular}

Data are $\mathrm{n}(\%)$ or $\mathrm{n} / \mathrm{N}(\%)$ unless noted otherwise. PUCAI=Pediatric Ulcerative Colitis Activity Index. TNF=tumour necrosis factor. *Evaluable population excludes participants who discontinued the study without additional therapy or colectomy. †Remission with faecal calprotectin $<250 \mu \mathrm{g} / \mathrm{g}$ is defined only within the subset with a stool sample. \#Fisher's exact test. SOne patient had colectomy with no additional therapy. $\uparrow$ Week 12 corticosteroid-free remission was defined as PUCAI <10 and no corticosteroids for 14 days without additional therapy or colectomy. $p$ values comparing groups are from a $\chi^{2}$ (unless noted otherwise) for categorical variables, a Mantel-Haenszel $\chi^{2}$ test for ordinal variables, and ANOVA or Kruskal-Wallis test for continuous variables.

Table 2: Clinical outcomes at weeks 4 and 12 by initial therapy

in the intravenous corticosteroid group, had colectomy by week 4 , with three not responding to infliximab and one having colectomy after intravenous corticosteroids only. Eight patients, all in the intravenous corticosteroid group, required colectomy by week 12 . Five of the 82 patients requiring additional medical therapy did so because of intolerance or side-effects thought t o b e related to mesalazine (one moderate rash and four worsening of symptoms). Seven other patients stopped mesalazine because of adverse reactions, but did not receive additional therapy beyond corticosteroids by week 12 (appendix p 25). Two additional patients received a thiopurine because of concomitant liver disease.

Clinical and laboratory measures reflecting increasing disease severity at baseline were associated with worse outcomes (table 3). Of particular note were two histological features: a baseline rectal biopsy peak eosinophil count of more than 32 cells per high-power field was associated with better outcomes and surface villiform changes were associated with worse outcomes. Age, sex, ethnicity, body-mass index, pANCA positivity, and baseline faecal calprotectin were not associated with outcome. However, week 4 faecal calprotectin was associated with week 12 outcome. Median baseline $25-\mathrm{OH}$ vitamin $\mathrm{D}$ was lower in patients requiring additional medical therapy by week 12 compared with the other groups $(\mathrm{p}=0 \cdot 047)$, but $25-\mathrm{OH}$ vitamin $\mathrm{D}$ lower than $20 \mathrm{ng} / \mathrm{mL}$ was not associated with outcome. Relationships with week 12 outcomes for the three initial therapy groups are shown in the appendix (pp 11-13), and associations between baseline characteristics and week 4 clinical outcomes are also shown for the full cohort (appendix p 14) and for each therapy group (appendix pp 15-17).

A multivariable model of baseline characteristics associated with week 4 remission for all three initial therapies, as well as additional medical therapy or 


\begin{tabular}{|c|c|c|c|c|}
\hline & $\begin{array}{l}\text { Week } 12 \\
\text { corticosteroid- } \\
\text { free remission } \\
(n=141)\end{array}$ & $\begin{array}{l}\text { Neither } \\
\text { corticosteroid- } \\
\text { free remission nor } \\
\text { additional therapy } \\
\text { or colectomy } \\
(n=193)\end{array}$ & $\begin{array}{l}\text { Additional } \\
\text { therapy or } \\
\text { colectomy } \\
(n=82)\end{array}$ & $p$ value \\
\hline \multicolumn{5}{|l|}{ Patient characteristics } \\
\hline Age (years) & $12 \cdot 2(3 \cdot 5)$ & $12 \cdot 9(3 \cdot 1)$ & $12 \cdot 9(3 \cdot 1)$ & 0.11 \\
\hline Sex & & & & 0.57 \\
\hline Girls & $72(51 \%)$ & $91(47 \%)$ & $44(54 \%)$ & .. \\
\hline Boys & $69(49 \%)$ & $102(53 \%)$ & $38(46 \%)$ & .. \\
\hline Non-white race & $24 / 139(17 \%)$ & $26 / 190(14 \%)$ & $15 / 79(19 \%)$ & 0.48 \\
\hline Body-mass index $Z$ score & $-0.1(1.2)$ & $-0.2(1 \cdot 2)$ & $-0.5(1.6)$ & 0.13 \\
\hline Admitted to hospital at baseline & $33(23 \%)$ & $73(38 \%)$ & $55(67 \%)$ & $<0.0001$ \\
\hline \multicolumn{5}{|l|}{ Baseline characteristics } \\
\hline $\begin{array}{l}\text { Total PUCAI (range } 0-85 \text { in } \\
\text { increments of } 5 \text { ) }\end{array}$ & $42 \cdot 0(19 \cdot 3)$ & $50 \cdot 6(18 \cdot 4)$ & $62 \cdot 1(17 \cdot 2)$ & $<0.0001$ \\
\hline $10-30$ (mild) & $50(35 \%)$ & $42(22 \%)$ & $6(7 \%)$ & $<0.0001$ \\
\hline 35-60 (moderate) & $62(44 \%)$ & $90(47 \%)$ & $30(37 \%)$ & .. \\
\hline$\geq 65$ (severe) & $29(21 \%)$ & $61(32 \%)$ & $46(56 \%)$ & .. \\
\hline Abdominal pain & $108(77 \%)$ & $163(84 \%)$ & $73(89 \%)$ & 0.041 \\
\hline Diarrhoea & $121(86 \%)$ & $181(94 \%)$ & $82(100 \%)$ & 0.00037 \\
\hline Rectal bleeding & $127(90 \%)$ & $181(94 \%)$ & $78(95 \%)$ & 0.29 \\
\hline Total Mayo score (0-12) & $7 \cdot 0(2 \cdot 4)$ & $7 \cdot 7(2 \cdot 3)$ & $9 \cdot 3(2 \cdot 2)$ & $<0.0001$ \\
\hline$\geq 10$ & $23(16 \%)$ & $51(26 \%)$ & $42(51 \%)$ & $<0.0001$ \\
\hline$\geq 11$ & $10(7 \%)$ & $23(12 \%)$ & $36(44 \%)$ & $<0.0001$ \\
\hline Mayo endoscopic subscore $(0-3)$ & $2 \cdot 1(0 \cdot 7)$ & $2 \cdot 1(0 \cdot 7)$ & $2.5(0.5)$ & $<0.0001$ \\
\hline Partial Mayo score (0-9) & $4.9(2.0)$ & $5 \cdot 6(1 \cdot 9)$ & $6 \cdot 8(1 \cdot 9)$ & $<0.0001$ \\
\hline Disease extent & & & & 0.00041 \\
\hline Proctosigmoiditis & $13(9 \%)$ & $15(8 \%)$ & 0 & .. \\
\hline Left-sided colitis & $21(15 \%)$ & $19(10 \%)$ & $3(4 \%)$ & .. \\
\hline $\begin{array}{l}\text { Extensive, pancolitis, } \\
\text { or unassessable }\end{array}$ & $107(76 \%)$ & $159(82 \%)$ & $79(96 \%)$ & .. \\
\hline Relative rectal sparing & 19/141 (13\%) & 14/192 (7\%) & $4 / 82(5 \%)$ & 0.053 \\
\hline Coecal patch & $16 / 135(12 \%)$ & 9/179 (5\%) & $4 / 72(6 \%)$ & 0.059 \\
\hline Non-specific macroscopic gastritis & 26/137 (19\%) & $53 / 189(28 \%)$ & $31 / 82(38 \%)$ & 0.0089 \\
\hline $\begin{array}{l}\text { Rectal biopsy eosinophilic } \\
\text { inflammation (>32 cells per } \\
\text { high-power field) }\end{array}$ & $73 / 125(58 \%)$ & $105 / 162(65 \%)$ & $26 / 69(38 \%)$ & 0.00066 \\
\hline $\begin{array}{l}\text { Rectal biopsy surface villiform } \\
\text { changes }\end{array}$ & $35 / 125(28 \%)$ & $57 / 161(35 \%)$ & $39 / 68(57 \%)$ & 0.00025 \\
\hline Rectal biopsy basal plasmacytosis & $52 / 116(45 \%)$ & $86 / 152(57 \%)$ & $32 / 58(55 \%)$ & 0.14 \\
\hline Haemoglobin (g/dL) & $11.9(1.9)$ & $11 \cdot 5(2 \cdot 2)$ & $10 \cdot 5(2 \cdot 4)$ & $<0.0001$ \\
\hline$<10$ & $19 / 131(15 \%)$ & $42 / 179(23 \%)$ & $35 / 81(43 \%)$ & $<0.0001$ \\
\hline Platelet count $\left(\times 10^{9}\right.$ cells per $\left.\mathrm{L}\right)$ & $362(286-434)$ & $355(297-473)$ & $410(345-496)$ & 0.0092 \\
\hline$>500$ & $18 / 130(14 \%)$ & $38 / 178(21 \%)$ & $20 / 80(25 \%)$ & $0 \cdot 10$ \\
\hline White blood count $\left(\times 10^{9}\right.$ cells per $\left.\mathrm{L}\right)$ & $\begin{array}{c}8 \cdot 9 \\
(7 \cdot 2-11 \cdot 3)\end{array}$ & $\begin{array}{c}9 \cdot 1 \\
(7 \cdot 0-11 \cdot 4)\end{array}$ & $\begin{array}{c}10 \cdot 6 \\
(8 \cdot 0-13 \cdot 8)\end{array}$ & 0.0048 \\
\hline$>12$ & $23 / 127(18 \%)$ & $42 / 178(24 \%)$ & $31 / 81(38 \%)$ & 0.0040 \\
\hline $\begin{array}{l}\text { Erythrocyte sedimentation rate } \\
(\mathrm{mm} / \mathrm{h})\end{array}$ & $22(11-39)$ & $23(12-38)$ & $36(22-53)$ & 0.00018 \\
\hline$\leq 20$ & $61 / 128(48 \%)$ & $82 / 171(48 \%)$ & $17 / 75(23 \%)$ & 0.00016 \\
\hline$>40$ & $30 / 128(23 \%)$ & $38 / 171(22 \%)$ & $31 / 75(41 \%)$ & .. \\
\hline CRP or hsCRP $>2 \times$ ULN & $24 / 101(24 \%)$ & $37 / 142(26 \%)$ & $34 / 67(51 \%)$ & $<0.0001$ \\
\hline Albumin (g/dL) & $3.9(0.6)$ & $3.6(0.7)$ & $3 \cdot 3(0 \cdot 7)$ & $<0.0001$ \\
\hline$<3.5$ & $32 / 140(23 \%)$ & $65 / 189(34 \%)$ & $40 / 81(49 \%)$ & 0.00028 \\
\hline
\end{tabular}

colectomy in patients who initiated with intravenous corticosteroids, is shown in the appendix ( $p$ 18).

For the full cohort, a total Mayo clinical and endoscopic severity score of less than 10 at diagnosis (OR 1.83, 95\% CI $1 \cdot 10-3 \cdot 06, \mathrm{p}=0 \cdot 020)$, proctosigmoiditis $(5 \cdot 00,1 \cdot 64-15 \cdot 22$, $\mathrm{p}=0.0046)$, relative rectal sparing $(4.49,1.75-11.47$, $\mathrm{p}=0 \cdot 0017)$, and rectal biopsy eosinophil peak count greater than 32 cells per high-power field $(1 \cdot 73,1 \cdot 10-2 \cdot 71$, $\mathrm{p}=0 \cdot 018$ ) were all associated with increased odds of week 4 clinical remission. Increasing serum albumin in increments of $1 \mathrm{~g} / \mathrm{dL}(1 \cdot 37,0 \cdot 99-1 \cdot 90, \mathrm{p}=0 \cdot 058)$, showed a predictive trend. The model from these five parameters had moderate predictive accuracy (AUC 0 70, 0.64-0.75).

In focusing on the intravenous corticosteroid group and looking for predictors for the use of additional medical therapy or colectomy by week 4 , the predictive model included total Mayo clinical and endoscopic severity score greater than or equal to 11 (OR $5 \cdot 50,95 \%$ CI $1 \cdot 85-16 \cdot 31$, $\mathrm{p}=0 \cdot 0021)$, decreasing serum albumin in increments of $1 \mathrm{~g} / \mathrm{dL}(3.86,1.58-9.44, \mathrm{p}=0.0031)$, rectal biopsy eosinophil count of less than or equal to 32 cells per high-power field $(7 \cdot 04,2 \cdot 21-22 \cdot 41, \mathrm{p}=0 \cdot 0010)$, and rectal biopsy surface villiform changes $(3 \cdot 16,1 \cdot 09-9 \cdot 14$, $\mathrm{p}=0.034)$. These factors provided strong predictive accuracy (AUC 0 87, 0 80-0.94).

Table 4 shows the multivariable model of baseline and week 4 characteristics associated with week 12 corticosteroid-free remission for all initial therapy groups and additional therapy or colectomy for patients treated with intravenous corticosteroids. For the full cohort and for each initial treatment group, the factor most consistently associated with corticosteroid-free remission was week 4 clinical remission, with the smallest effect with mesalazine and the largest effect with intravenous corticosteroids. For the full cohort, other baseline predictive factors for corticosteroid-free remission included PUCAI less than 35 and increasing serum albumin by $1 \mathrm{~g} / \mathrm{dL}$ increments in children younger 12 years (table 4 ).

By focusing on the intravenous corticosteroid group and looking for predictors for the use of additional medical therapy or colectomy by week 12 , we identified a predictive model that included initial total Mayo score greater than or equal to 11 (factor included because of its clinical relevance), rectal biopsy eosinophil count less than or equal to 32 cells per high-power field, the presence of surface villiform changes, and the absence of remission by week 4 (table 4). Together, these factors provided strong predictive accuracy (AUC $0 \cdot 89,95 \%$ CI $0 \cdot 83-0 \cdot 95$ ). If the analysis is limited to examination of patients who received intravenous corticosteroids and then infliximab or a calcineurin inhibitor or colectomy (patients taking immunomodulators were excluded) by week 12 , the predictive model is essentially the same as that for week 4 , because 37 of the 40 participants who initiated on intravenous corticosteroids and received infliximab had received it before week 4 . Model parameter 
estimates are shown in the appendix (pp 19, 20), as are ROC curves and calibration plots (pp 23, 24).

In our internal validation, the results from bootstrapping and multiple imputation were generally supportive of the final selected models, as described in the appendix (p 8, 9, 21, 22). The size of the ORs was attenuated (but with $\mathrm{p}<0.05)$ in the imputation models for proctosigmoiditis (week 4 and full cohort), relative rectal sparing (week 4 full cohort and oral corticosteroids), and rectal biopsy eosinophil peak count (week 4 additional therapy among patients who started on intravenous corticosteroid).

\section{Discussion}

PROTECT is, to our knowledge, the first multicentre inception cohort study to report factors associated with early responses to standardised first-line therapy in treatment-naive paediatric ulcerative colitis. Our data reveal a sobering early course for children with new-onset ulcerative colitis. Corticosteroid-free remission at week 12 after diagnosis without the need for therapy with immunomodulators, anti-TNF agents, or colectomy occurred in $48 \%$ of children initially treated with mesalazine for mild to lower moderate intensity disease. Week 12 remission was only achieved by $33 \%$ of patients with moderate disease who initially started on oral corticosteroids, and this value was even lower at $21 \%$ among those admitted to hospital with severe disease who initially started on intravenous corticosteroids. It is possible that these numbers were affected $\mathrm{b}$ y a $\mathrm{n}$ a ggressive a ttempt to lower a nd then stop corticosteroid use by 10 weeks after diagnosis.

Comparison of our results to outcomes in adults following mesalazine or corticosteroid therapy is difficult gi ven th at ou $\mathrm{r}$ st udy po pulation wa s ne wly diagnosed and treatment naive and we used standardised dosing regimens. Compared with previous adult and paediatric studies, we used a relatively high mesalazine dosing schedule of about $67 \mathrm{mg} / \mathrm{kg}$ per day (maximum $4 \mathrm{~g}$ ) because previous work in adults has suggested improved outcomes with increased dosing schedules. ${ }^{21}$ The proportions of patients achieving a response to a first course of corticosteroids by 4 weeks in adults with ulcerative colitis (not necessarily at diagnosis) are $40-50 \%,{ }^{7,10}$ which is similar to our results in children. In those studies, ${ }^{7,10}$ higher initial Mayo scores and extensive disease were predictors of non-response and need for additional medical therapy or colectomy. Our finding of $26 \%$ of c hildren in the intravenous corticosteroid group needing additional medical therapy is similar to that from a previous report ${ }^{2}$ on children with acute severe colitis (29\%) who were treated with intravenous corticosteroids at presentation or following an exacerbation of previously diagnosed disease.

Follow-up endoscopic evaluation was not part of the treatment protocol or routinely done by week 12 and therefore endoscopic improvement or healing rates are

\begin{tabular}{|c|c|c|c|c|}
\hline & $\begin{array}{l}\text { Week } 12 \\
\text { corticosteroid- } \\
\text { free remission } \\
(n=141)\end{array}$ & $\begin{array}{l}\text { Neither } \\
\text { corticosteroid- } \\
\text { free remission } \\
\text { nor additional } \\
\text { therapy } \\
\text { or colectomy } \\
(n=193)\end{array}$ & $\begin{array}{l}\text { Additional } \\
\text { therapy or } \\
\text { colectomy } \\
(n=82)\end{array}$ & $\mathrm{p}$ value \\
\hline \multicolumn{5}{|l|}{ (Continued from previous page) } \\
\hline \multicolumn{5}{|l|}{ Faecal calprotectin* $(\mu \mathrm{g} / \mathrm{g})$} \\
\hline Patients with data & 78 & 110 & 48 & \\
\hline Median (IQR) & $\begin{array}{l}2195 \\
(1202-3663)\end{array}$ & $\begin{array}{l}2002 \\
(1180-4043)\end{array}$ & $\begin{array}{l}3015 \\
(1532-3892)\end{array}$ & 0.43 \\
\hline Faecal osteoprotegerin $(\mathrm{pg} / \mathrm{mL})^{*}$ & $119(31-1460)$ & $508(31-3220)$ & $1208(205-6427)$ & 0.015 \\
\hline$>1000$ & $14 / 54(26 \%)$ & $39 / 90(43 \%)$ & $17 / 33(52 \%)$ & 0.049 \\
\hline 25-OH Vitamin D (ng/mL) & $\begin{array}{c}28 \cdot 8 \\
(24 \cdot 5-35 \cdot 3)\end{array}$ & $\begin{array}{c}28 \cdot 8 \\
(24 \cdot 8-35 \cdot 7)\end{array}$ & $\begin{array}{c}26 \cdot 6 \\
(22 \cdot 2-31 \cdot 1)\end{array}$ & 0.047 \\
\hline$<20$ (deficient) & $12 / 133(9 \%)$ & $16 / 173(9 \%)$ & $11 / 75(15 \%)$ & 0.37 \\
\hline \multicolumn{5}{|l|}{ pANCA (EU/mL) } \\
\hline Positive titre & $89 / 134(66 \%)$ & $110 / 174(63 \%)$ & $54 / 77(70 \%)$ & 0.56 \\
\hline$\geq 100$ & $22 / 134(16 \%)$ & $33 / 174(19 \%)$ & $19 / 77(25 \%)$ & 0.34 \\
\hline OmpC (EU/mL) & $\begin{array}{c}7 \cdot 1 \\
(4 \cdot 9-10 \cdot 4)\end{array}$ & $\begin{array}{c}7 \cdot 0 \\
(5 \cdot 3-10 \cdot 3)\end{array}$ & $\begin{array}{c}8 \cdot 8 \\
(6 \cdot 3-13 \cdot 2)\end{array}$ & 0.014 \\
\hline Positive titre & $5 / 134(4 \%)$ & $12 / 174(7 \%)$ & $3 / 77(4 \%)$ & $0.45 \dagger$ \\
\hline$\geq 12$ & 24/134 (18\%) & $33 / 174(19 \%)$ & $22 / 77(29 \%)$ & 0.14 \\
\hline \multicolumn{5}{|l|}{ Week 4 characteristics } \\
\hline Week 4 remission & $109(77 \%)$ & $91(47 \%)$ & $8(10 \%)$ & $<0.0001$ \\
\hline $\begin{array}{l}\text { Week } 4 \text { remission with faecal } \\
\text { calprotectin* }<250 \mu \mathrm{g} / \mathrm{g}\end{array}$ & $35 / 100(35 \%)$ & $19 / 135(14 \%)$ & $1 / 46(2 \%)$ & $<0.0001$ \\
\hline $\begin{array}{l}\text { Week } 4 \text { additional therapy or } \\
\text { colectomy }\end{array}$ & 0 & 0 & $45(55 \%)$ & $<0.0001$ \\
\hline \multicolumn{5}{|c|}{ Week 4 PUCAI score (0-85 in increments of 5$)$} \\
\hline Patients with data & 138 & 193 & 76 & \\
\hline Mean (SD) & $4 \cdot 8(7 \cdot 3)$ & $12 \cdot 6(15 \cdot 6)$ & $20 \cdot 1(20 \cdot 0)$ & $<0.0001$ \\
\hline \multicolumn{5}{|c|}{ Week 4 partial Mayo score (range 0-9) } \\
\hline Patients with data & 120 & 168 & 67 & \\
\hline Mean (SD) & $0 \cdot 7(1.1)$ & $1 \cdot 5(1 \cdot 7)$ & $2 \cdot 3(2 \cdot 2)$ & $<0.0001$ \\
\hline \multicolumn{5}{|l|}{ Week 4 albumin $(\mathrm{g} / \mathrm{dL})$} \\
\hline Patients with data & 104 & 149 & 67 & \\
\hline Mean (SD) & $4 \cdot 3(0 \cdot 4)$ & $4 \cdot 2(0.5)$ & $3 \cdot 8(0 \cdot 6)$ & $<0.0001$ \\
\hline Week 4 CRP or hsCRP $>2 \times$ ULN & $1 / 85(1 \%)$ & $6 / 109(6 \%)$ & $9 / 55(16 \%)$ & $0.0018 \dagger$ \\
\hline \multicolumn{5}{|c|}{ Week 4 erythrocyte sedimentation rate $(\mathrm{mm} / \mathrm{h})$} \\
\hline Patients with data & 101 & 135 & 66 & \\
\hline Median (IQR) & $10(6-17)$ & $9(6-18)$ & $18(8-35)$ & 0.00085 \\
\hline \multicolumn{5}{|l|}{ Week 4 faecal calprotectin* $(\mu \mathrm{g} / \mathrm{g})$} \\
\hline Patients with data & 100 & 135 & 46 & \\
\hline Median (IQR) & $\begin{array}{c}476 \\
(171-1432)\end{array}$ & $\begin{array}{c}989 \\
(237-1754)\end{array}$ & $\begin{array}{l}1862 \\
(1151-3659)\end{array}$ & $<0.0001$ \\
\hline
\end{tabular}

Data are $\mathrm{n}(\%), \mathrm{n} / \mathrm{N}(\%), \mathrm{n}$, mean (SD), or median (IQR), unless noted otherwise. p values comparing groups are from a $\chi^{2}$ test (unless noted otherwise) for categorical variables, a Mantel-Haenszel $\chi^{2}$ test for ordinal variables, and ANOVA or Kruskal-Wallis test for continuous variables. PUCAI=Pediatric Ulcerative Colitis Activity Index. CRP=C-reactive protein. ULN=upper limit of normal. EU=endotoxin units. pANCA=perinuclear anti-neutrophil cytoplasmic antibody. $\mathrm{OmpC}=$ outer membrane precursor protein C. *Results limited to stool collected prior to 4 days of initial treatment, and before or after colonoscopy cleanout. †Fisher's exact test.

Table 3: Baseline and week 4 clinical and demographic characteristics by week 12 outcome

not available. However, we did longitudinal measurement of faecal calprotectin as a surrogate of mucosal healing. $95 \%$ of patients in our inception cohort who provided a 
(all patients; $\mathrm{n}=409)^{*}$

Additional therapy or colectomy (intravenous corticosteroids only; $n=141$ )

Mesalazine Oral corticosteroid Intravenous

$\begin{array}{lll}\begin{array}{l}\text { Mesalazine } \\ (n=129)\end{array} & (n=139) & \text { Intravenous } \\ \text { corticosteroids }(n=141)\end{array}$

\begin{tabular}{|c|c|c|c|c|c|}
\hline \multicolumn{6}{|l|}{ Population } \\
\hline Model sample size & 403/409 (99\%) & $116 / 129(90 \%)$ & $139 / 139(100 \%)$ & $119 / 141(84 \%)$ & $119 / 141(84 \%)$ \\
\hline Number of events & $140 / 403(35 \%)$ & $57 / 116(49 \%)$ & $47 / 139(34 \%)$ & $26 / 119(22 \%)$ & $42 / 119(35 \%)$ \\
\hline \multicolumn{6}{|l|}{ Baseline predictors } \\
\hline Lower PUCAI & .. &.$\cdot$ & .. & .. &.$\cdot$ \\
\hline$<35$ & $\begin{aligned} & 2 \cdot 44(1 \cdot 41-4 \cdot 22), \\
p= & 0 \cdot 0015\end{aligned}$ & .. & .. & .. &. \\
\hline$<45$ & .. & .. & $\begin{aligned} & 4.38(1.81-10 \cdot 60), \\
p= & 0.0011\end{aligned}$ & .. & .. \\
\hline Total Mayo score $\geq 11$ & .. &.. & .. & .. & $\begin{aligned} & 2.59(0.93-7.21) \\
p= & 0.068\end{aligned}$ \\
\hline \multicolumn{6}{|c|}{ Higher albumin per $1 \mathrm{~g} / \mathrm{dL}$ increase (interaction with age) $\dagger$} \\
\hline Age $<12$ years & $\begin{aligned} & 4.05(1.90-8.64) \\
p= & 0.00030\end{aligned}$ & .. & .. & .. & .. \\
\hline Age $\geq 12$ years & $\begin{array}{l}1.13(0 \cdot 74-1 \cdot 71), \\
p=0.57\end{array}$ &.. & .. &.. &.. \\
\hline Haemoglobin $\geq 12 \mathrm{~g} / \mathrm{dL}$ & .. & $\begin{array}{l}2.19(0.96-4.97), \\
p=0.062\end{array}$ & .. & .. & .. \\
\hline $\begin{array}{l}\text { Rectal biopsy eosinophil peak count } \\
\leq 32 \text { cells per high-power field }\end{array}$ &.. &.. & .. &.. & $\begin{array}{l}4.55(1.62-12 \cdot 78), \\
p=0.0040\end{array}$ \\
\hline \multicolumn{6}{|l|}{ Rectal biopsy surface villiform changes } \\
\hline No changes &.$\cdot$ &.. & .. & $\begin{array}{l}2 \cdot 71(0.97-7.56), \\
p=0.057\end{array}$ &.. \\
\hline Changes &.$\cdot$ &.. & .. & .. & $\begin{aligned} & 3.05(1.09-8.56), \\
p= & 0.034\end{aligned}$ \\
\hline \multicolumn{6}{|l|}{ Week 4 remission } \\
\hline Yes & $\begin{array}{l}\quad 6.26(3 \cdot 79-10 \cdot 35), \\
p<0.0001\end{array}$ & $\begin{array}{l}3.69(1 \cdot 67-8 \cdot 15), \\
p=0.0013\end{array}$ & $\begin{array}{l}8.02(3.11-20 \cdot 70) \\
p<0.0001\end{array}$ & $\begin{array}{l}7.48(2 \cdot 67-20 \cdot 96) \\
p=0.00013\end{array}$ &.. \\
\hline No & .. & .. & .. & .. & $\begin{array}{l}30 \cdot 28(6 \cdot 36-144 \cdot 20) \\
p<0 \cdot 0001\end{array}$ \\
\hline \multicolumn{6}{|l|}{ Assessments of model fit } \\
\hline AUC & $0.79(0.74-0.84)$ & $0.70(0.61-0.79)$ & $0.78(0.71-0.86)$ & $0.77(0.67-0.88)$ & $0.89(0.83-0.95)$ \\
\hline Adjusted AUC & $0.78(0.73-0.83)$ & $0.70(0.61-0.79)$ & $0.78(0.71-0.86)$ & $0.77(0.67-0.88)$ & $0.88(0.82-0.94)$ \\
\hline $\mathrm{R}^{2}$ & $0 \cdot 31$ & $0 \cdot 18$ & 0.32 & $0 \cdot 26$ & 0.54 \\
\hline Sensitivity & $41 \%(33-50)$ & $54 \%(41-68)$ & $40 \%(26-56)$ & $62 \%(41-80)$ & $71 \%(55-84)$ \\
\hline Specificity & $89 \%(85-92)$ & $61 \%(47-73)$ & $93 \%(86-98)$ & $86 \%(77-92)$ & $86 \%(76-93)$ \\
\hline Positive predictive value & $67 \%(56-76)$ & $57 \%(43-71)$ & $76 \%(55-91)$ & $55 \%(36-74)$ & $73 \%(57-86)$ \\
\hline Negative predictive value & $74 \%$ (69-79) & $58 \%(45-70)$ & $75 \%(66-83)$ & $89 \%(81-95)$ & $85 \%(75-92)$ \\
\hline \multicolumn{6}{|c|}{$\begin{array}{l}\text { Data are } \mathrm{n} / \mathrm{N}(\%) \text {, odds ratio }(95 \% \mathrm{Cl}) \text {, or } \%(95 \% \mathrm{Cl}) \text { unless noted otherwise. Further models for the full cohort identified an interaction between mild baseline PUCAI (10-30) } \\
\text { and week } 4 \text { remission }(\mathrm{p}=0.05) \text {, indicating that the effect of week } 4 \text { remission on week } 12 \text { remission is less strong for participants with a mild baseline PUCAI. The interaction } \\
\text { was not included in the model because there was no improvement in the model AUC. Potential covariates were excluded from the model on the basis of internal validation: } \\
\text { ANCA positivity was excluded in the mesalazine and oral corticosteroid groups because of clinical inconsistency between subgroups and across assessment times, whereas } \\
\text { OmpC }<12 \mathrm{EU} / \mathrm{mL} \text { was excluded from analysis of additional therapy or colectomy in the intravenous corticosteroid group because of the absence of association in the } \\
\text { multiple imputation model. AUC=area under the curve. Adjusted AUC=AUC with bootstrap adjustment for optimism of model estimation. PUCAI=Pediatric Ulcerative Colitis } \\
\text { Activity Index. EU=endotoxin units. ANCA= anti-neutrophil cytoplasmic antibodies. OmpC=outer membrane precursor protein C. *N is the number evaluable at week } 12 \text { and } \\
\text { with no protocol violations. †For the full cohort, } \mathrm{p}=0.004 \text { for the interaction between age }<12 \text { years and albumin. }\end{array}$} \\
\hline
\end{tabular}

Table 4: Multivariable logistic regression models of week 12 outcomes by treatment type

stool sample had a faecal calprotectin greater than or equal to $250 \mu \mathrm{g} / \mathrm{g}$ at diagnosis. At week $12,20 \%$ of all patients from whom stool was obtained had faecal calprotectin less than $250 \mu \mathrm{g} / \mathrm{g}$ and were in corticosteroidfree remission, ranging from $28 \%$ of those initially treated with mesalazine to $17 \%$ of those treated with oral corticosteroids, and $16 \%$ of those treated with intravenous corticosteroids. These data suggest that mucosal healing can occur by week 12 in patients in clinical and corticosteroid-free remission, respectively, but is unusual 
in patients with new-onset ulcerative colitis treated with standardised mesalazine or corticosteroid therapy.

Our exploratory modelling supported previous observations of the importance of initial disease severity and extent in predicting disease course in both children and adults. ${ }^{47,22,23}$ In our study and in previous work, ${ }^{6,7}$ initial serum albumin was associated with disease outcome, with lower concentrations being associated with worse outcomes. Our results also support the usefulness of baseline total Mayo clinical and endoscopic severity score in identifying patients who are less likely to achieve week 4 remission with corticosteroids alone.

We found that the number of eosinophils on rectal biopsy correlated with clinical outcomes. On the basis of previous observations, ${ }^{14}$ we classified r ectal b iopsy e osinophilia a s peak eosinophil count less than or equal to 32 cells per high-power field or as peak eosinophil count greater than 32 cells per high-power field: ${ }^{14}$ more than half of our study participants had counts in the higher classification. Mucosal eosinophilia in ulcerative colitis has been reported previously in both adults ${ }^{24-26}$ and children. ${ }^{27,28}$ Although previous paediatric data revealed a positive correlation between rectosigmoid eosinophil numbers and disease severity, ${ }^{27}$ adult studies have suggested that decreased eosinophil counts at rectal biopsy are associated with medically refractory disease. ${ }^{24,26}$ Notably, the adult studies included patients on therapy, including corticosteroids, which might have reduced tissue eosinophilia, whereas our study included only treatment-naive patients. The role of eosinophils in disease pathogenesis continues to be explored. Another study suggested a role for type 2 immune responses, including tissue eosinophilia, in improved responses to therapy in paediatric ulcerative colitis and wound healing. ${ }^{29}$ Rectal expression of a panel of type 2 immune genes, including interleukin 5 and interleukin 13 , measured at diagnosis of paediatric ulcerative colitis was associated with a higher proportion of patients achieving steroid-free remission. The paradoxical finding from o ur work that decreased tissue eosinophil numbers were associated with greater likelihood of refractory disease thus remains unexplained, but is consistent with earlier adult and more recent paediatric studies..$^{24,26}$

We also noted that surface villiform changes on rectal biopsy were associated with the need for additional medical therapy or colectomy in patients initially treated with intravenous corticosteroids. To our knowledge this association has not been reported previously and might reflect the $n$ ature of e pithelial $d$ amage in s evere c linical disease. This result was not simply a reflection of higher clinical and endoscopic severity, because a multivariable model that included total Mayo score identified a $n$ independent association between surface villiform changes and increased likelihood of treatment escalation. Future studies using concurrent rectal microbial community and gene expression data should seek to determine the specific biological pathways associated with this adverse histological feature.
Our study has several strengths, but also some limitations. Strengths include the large multicentre prospective inception cohort design, standardised guidelines for initial therapy, and well validated clinical outcome measures. However, patient selection was not population-based and disease severity distribution might have been biased at selected centres that enrolled more or less ill patients. Therefore, the roughly one-third distribution of mild, moderate, and severe disease, respectively, noted in our inception cohort might not be representative of all paediatric ulcerative colitis. Despite the use of protocol-guided standardised initial therapy based on disease severity, the ultimate treatment selection was left to the discretion of the clinician and patients' families, and the protocol guidelines were initiated successfully in two-thirds of our study population. The predictive models for initial treatment subgroups are based on a smaller sample size than the entire cohort. We did not do external validation for the presented prediction models. Additionally, the models could potentially be affected by the pattern of missing data across the covariates. The lower than anticipated collection rate for stool samples at all timepoints limited our ability to use faecal calprotectin and faecal osteoprotegerin in the final predictive modelling. Novel interventions will be needed to improve stool collection in future studies. Similar constraints occurred with the low availability of standard-of-care CRP measurements at baseline.

We have documented early response rates to standardised mesalazine and corticosteroids in phenotyped subgroups of children with newly diagnosed ulcerative colitis, and identified candidate predictors for early remission or the need for medical therapy beyond mesalazine and corticosteroids. Our results show that clinical activity indices, including PUCAI and Mayo score, can be combined with serum albumin and specific histological features of rectal biopsies to judge the likelihood of success for first-line therapies, and that week 4 remission is a crucial juncture to guide additional therapies. These data suggest that additional therapeutic interventions could be warranted to improve early outcomes, especially in children presenting with severe disease and requiring treatment with intravenous corticosteroids.

Contributors

ISH, SD, AM, SK, TW, and LAD designed the study, oversaw its conduct, acquired and analysed the data, drafted the initial manuscript, and critically revised the final manuscript. DRM, BB, AMG, NSL, CGS, DJK, JM, SSB, JR, RNB, AP, MP, AO, MH, JN, MO-H, PR, JSt, JSe, DZ, SLG, $\mathrm{BS}, \mathrm{KB}, \mathrm{PW}, \mathrm{DM}$, JE, and MDK acquired data, participated in analysis, and critically revised the final manuscript. FAS designed the study, acquired and analysed data, and critically revised the final manuscript. MHC, MD and VT acquired data, analysed the data and critically revised the final manuscript. SV, KLS, AB, BS, NG, JW, JSt, and JSe analysed the data and critically revised the final manuscript.

Declaration of interests

JSH has served on an advisory board for Janssen and is acting as a consultant for Abbvie, Takeda, Lilly, Boehringer Ingelheim, Allergan, and Astra Zeneca. SD has served on an independent data monitoring 
For more on the PROTECT study see http://www.protectstudy.com committee for Lycera Corporation. LAD has received grant support from AbbVie and Janssen. DRM has served on advisory boards for Abbvie and Janssen, acted as a consultant for UVB, and is an owner and holds shares in Biotagenics. NSL has acted as a consultant for Abbvie. AP has participated in speakers bureaus for Abbvie and Janssen. JM has acted as a consultant for Janssen, UCB, and Lilly. AMG declares research support from Abbvie, has acted as a consultant for Abbvie, Janssen, Merck, and Takeda, and has been a speaker for Abbvie and Janssen. JR has acted as a consultant for Abbvie, Janssen, Luitpold, and UCB, and has received grant funding from Janssen and Abbive. AO has served on advisory boards for Janssen and Abbvie, and has received research support from Abbvie, Janssen, Shire, and Astellas. MDK has acted as a consultant for Abbvie, Janssen, GlaxoSmithKline, and Pfizer. MD has acted as a consultant for Prometheus Laboratories. PR has acted as a consultant for Shire and Leutpold, has been a speaker for Abbvie, and has received research support from TechLab. CGS has acted as a consultant for Abbvie. SK has acted as a consultant for Janssen and UCB. JSt has acted as a consultant and speaker for Abbvie. MH reports research grants from Genentech, Abbvie, Sucampo, and Janssen. All other authors declare no competing interests.

\section{Acknowledgments}

Support for this study was provided by the NIH via the National Institute of Diabetes and Digestive and Kidney Diseases (NIDDK) 5U01DK095745 and P30 DK078392, Integrative Morphology Core. Further details about the study are available online. We thank Frank Hamilton and Stephen James from NIDDK for their guidance, and William Faubion for his role as safety monitor. The study investigators are deeply indebted to Shire Pharmaceuticals for providing Pentasa (mesalazine) for this study, to the research coordinators at the investigative sites for their tireless attention, and to the patients and families who agreed to participate in this important study.

\section{References}

1 Gower-Rousseau C, Dauchet L, Vernier-Massouille G, et al. The natural history of pediatric ulcerative colitis: a population-based cohort study. Am J Gastroenterol 2009; 104: 2080-88.

2 Turner D, Mack D, Leleiko N, et al. Severe pediatric ulcerative colitis: a prospective multicenter study of outcomes and predictors of response. Gastroenterology 2010; 138: 2282-91.

3 Schechter A, Griffiths C, Gana JC, et al. Early endoscopic, laboratory and clinical predictors of poor disease course in paediatric ulcerative colitis. Gut 2015; 64: 580-88.

4 Hyams JS, Davis P, Grancher K, et al. Clinical outcome of ulcerative colitis in children. J Pediatr 1996; 129: 81-88.

5 Zeisler B, Lerer T, Markowitz I, et al. Outcome following aminosalicylate therapy in children newly diagnosed as having ulcerative colitis. J Pediatr Gastroenterol Nutr 2013; 56: 12-18.

6 Kelley-Quon LI, Jen HC, Ziring DA, et al. Predictors of proctocolectomy in children with ulcerative colitis. J Pediatr Gastroenterol Nutr 2012; 55: 534-40.

7 Ho GT, Mowat C, Goddard CJ, et al. Predicting the outcome of severe ulcerative colitis: development of a novel risk score to aid early selection of patients for second-line medical therapy or surgery. Aliment Pharmacol Ther 2004; 19: 1079-87.

8 Melson JE, Giusto D, Kwasny M, et al. Histopathology predictors of medically refractory ulcerative colitis. Dis Colon Rectum 2010; 53: $1280-86$

9 Haritunians T, Taylor KD, Targan SR, et al. Genetic predictors of medically refractory ulcerative colitis. Inflamm Bowel Dis 2010; 16: $1830-40$

10 Yoon JY, Cheon JH, Park JJ, et al. Clinical outcomes and factors for response prediction after the first course of corticosteroid therapy in patients with active ulcerative colitis. J Gastroenterol Hepatol 2011; 26: $1114-22$.
11 Turner D, Otley AR, Mack D, et al. Development, validation, and evaluation of a pediatric ulcerative colitis activity index: a prospective multicenter study. Gastroenterology 2007; 133: 423-32.

12 North American Society for Pediatric Gastroenterology, Hepatology, and Nutrition, Colitis Foundation of America, Bousvaros A, et al. Differentiating ulcerative colitis from Crohn disease in children and young adults: report of a working group of the North American Society for Pediatric Gastroenterology, Hepatology, and Nutrition and the Crohn's and Colitis Foundation of America. J Pediatr Gastroenterol Nutr 2007; 44: 653-74.

13 Schroeder KW, Tremaine WJ, Ilstrup DM. Coated oral 5-aminosalicylic acid therapy for mildly to moderately active ulcerative colitis. A randomized study. N Engl J Med 1987; 317: 1625-29.

14 DeBrosse CW, Case JW, Putnam PE, et al. Quantity and distribution of eosinophils in the gastrointestinal tract of children. Pediatr Dev Pathol 2006; 9: 210-18.

15 Lee MJ, Kearns MD, Smith EM, et al. Free 25-hydroxyvitamin D concentrations in cystic fibrosis. Am J Med Sci 2015; 350: 374-79.

16 Burri E, Manz M, Rothen C, et al. Monoclonal antibody testing for fecal calprotectin is superior to polyclonal testing of fecal calprotectin and lactoferrin to identify organic intestinal disease in patients with abdominal discomfort. Clin Chim Acta 2013; 416: 41-47.

17 Nahidi L, Leach ST, Sidler MA, et al. Osteoprotegerin in pediatric Crohn's disease and the effects of exclusive enteral nutrition. Inflamm Bowel Dis 2011; 17: 516-23.

18 Dubinsky MC, Kugathasan S, Mei L, et al. Increased immune reactivity predicts aggressive complicating Crohn's disease in children. Clin Gastroenterol Hepatol 2008; 6: 1105-11.

19 von Elm E, Altman DG, Egger M, et al. The strengthening the reporting of observational studies in epidemiology (STROBE) statement: guidelines for reporting observational studies. Bull World Health Organ 2007; 85: 867-72.

20 Collins GS, Reitsma JB, Altman DG, et al. Transparent reporting of a multivariable prediction model for individual prognosis or diagnosis (TRIPOD): the TRIPOD statement. BMJ 2015; 350: g7594.

21 Hanauer SB, Sandborn WJ, Kornbluth A, et al. Delayed-release ora mesalamine at $4.8 \mathrm{~g} /$ day $(800 \mathrm{mg}$ tablet) for the treatment of moderately active ulcerative colitis: the ASCEND II trial. Am J Gastroenterol 2005; 100: 2478-85.

22 Moore JC, Thompson K, Lafleur B, et al. Clinical variables as prognostic tools in pediatric-onset ulcerative colitis: a retrospective cohort study. Inflamm Bowel Dis 2011; 17: 15-21.

23 Romberg-Camps MJ, Dagnelie PC, Kester AD, et al. Influence of phenotype at diagnosis and of other potential prognostic factors on the course of inflammatory bowel disease. Am J Gastroenterol 2009; 104: 371-83.

24 Heatley RV, James PD. Eosinophils in the rectal mucosa. A simple method of predicting the outcome of ulcerative proctocolitis? Gut 1979; 20: 787-91.

25 Willoughby CP, Piris J, Truelove SC. Tissue eosinophils in ulcerative colitis. Scand J Gastroenterol 1979; 14: 395-99.

26 Tanaka M, Saito H, Kusumi T, et al. Biopsy pathology predicts patients with ulcerative colitis subsequently requiring surgery. Scand J Gastroenterol 2002; 37: 200-05.

27 Ahrens R, Waddell A, Seidu L, et al. Intestinal macrophage/epithelia cell-derived CCL11/eotaxin-1 mediates eosinophil recruitment and function in pediatric ulcerative colitis. J Immunol 2008; 181: 7390-99.

28 Robert ME, Tang L, Hao LM, et al. Patterns of inflammation in mucosal biopsies of ulcerative colitis: perceived differences in pediatric populations are limited to children younger than 10 years. Am J Surg Pathol 2004; 28: 183-89.

29 Rosen MJ, Karns R, Vallance JE, et al. Mucosal expression of type 2 and type 17 immune response genes distinguishes ulcerative colitis from colon-only crohn's disease in treatment-naive pediatric patients. Gastroenterology 2017; 152: 1345-57. 